\title{
Cryogenic Propellant Tank and Feedline Design Studies in the Framework of the CHATT Project
}

\author{
Tobias Schwanekamp ${ }^{1}$, Carina Ludwig ${ }^{2}$ and Martin Sippel ${ }^{3}$ \\ German Aerospace Center (DLR), Space Launcher Systems Analysis (SART) of the Institute of Space Systems, \\ 28359 Bremen, Germany
}

\begin{abstract}
The EU-funded project CHATT (Cryogenic Hypersonic Advanced Tank Technologies) has been initiated early 2012 and is part of the European Commission's Seventh Framework Programme (FP7). CHATT focuses on the development of novel cryogenic tank and propellant supply technologies. One of the tasks within the project is the investigation of adequate propellant crossfeed systems. Propellant crossfeed principally allows large mass savings for parallel burn vehicles such as the visionary passenger transport concept "SpaceLiner" which has been proposed by the Space Launcher Systems Analysis Department of the German Aerospace Center DLR. Therefore the tank and feedline systems of the SpaceLiner concept are studied by means of reference data and the results of simulations conducted with in-house and commercial tools.
\end{abstract}

\section{Nomenclature}

$\begin{array}{ll}\text { CFRP } & =\text { Carbon Fiber Reinforced Plastic } \\ \text { GH2 } & =\text { Gaseous Hydrogen } \\ \text { GLOW } & =\text { Gross Lift-Off Weight } \\ \text { GOX } & =\text { Gaseous Oxygen } \\ \text { LH2 } & =\text { Liquid Hydrogen } \\ \text { LOX } & =\text { Liquid Oxygen } \\ \text { MECO } & =\text { Main Engine Cut-Off } \\ \text { NPSP } & =\text { Net Positive Suction Pressure } \\ \text { PMP } & =\text { Propellant Management Program } \\ \text { TPS } & =\text { Thermal Protection System } \\ \text { SL7 } & =\text { SpaceLiner 7 } \\ \text { SLME } & =\text { SpaceLiner Main Engines } \\ \text { SSME } & =\text { Space Shuttle Main Engines }\end{array}$

$\begin{array}{ll}\varepsilon=\text { Expansion ratio } & - \\ \mathrm{g}_{0}=\text { Gravitational acceleration } & 9.81 \mathrm{~m} / \mathrm{s}^{2} \\ \mathrm{I}_{\mathrm{sp}}=\text { Specific impulse } & \mathrm{s} \\ \mathrm{n}_{\mathrm{x}}=\text { Load factor in } \mathrm{x} \text { direction } & - \\ \mathrm{n}_{\mathrm{z}}=\text { Load factor in } \mathrm{z} \text { direction } & - \\ \mathrm{n}_{\text {tot }}=\text { Total load factor } & - \\ \mathrm{p}=\text { Pressure } & \mathrm{Pa} \\ \mathrm{t}=\text { Time } & \mathrm{s} \\ \Delta \mathrm{v}=\text { Velocity difference } & \mathrm{m} / \mathrm{s}\end{array}$

\section{Introduction}

$\mathrm{W}$ ITH the SpaceLiner vehicle, the DLR has proposed a visionary concept for hypersonic passenger transport over extremely long distances ${ }^{1,2}$. The SpaceLiner in its current version is shown in Figure 1. Connecting large business centers located on different continents could offer a considerable market potential for high speed passenger transport. To be successful, the concept must, of course, comply with a certain amount of efficiency and profitability.

\footnotetext{
${ }^{1}$ Research Scientist, German Aerospace Center, Institute of Space Systems, Space Launcher System Analysis, Robert-Hooke-Str. 7, 28359 Bremen, Germany.

${ }^{2} \mathrm{PhD}$ Candidate, German Aerospace Center, Institute of Space Systems, Space Launcher System Analysis, RobertHooke-Str. 7, 28359 Bremen, Germany.

${ }^{3}$ Head of Department, German Aerospace Center, Institute of Space Systems, Space Launcher System Analysis, Robert-Hooke-Str. 7, 28359 Bremen, Germany.
} 
For spacecraft systems it is a matter of knowledge that the cost of a launch is directly related to the total mass that needs to be lifted. Therefore, for a system like the SpaceLiner, where cost determines the feasibility of the project, it becomes extremely important to minimize the total mass of the system. Commonality of propellants between orbiter and booster allows for the use of propellant crossfeeding from the booster tanks to the orbiter engines, hence reducing the overall size and therefore the Gross Lift-Off Weight (GLOW) of the vehicle, while allowing for orbiter engine ignition on the ground. Crossfeeding in conjunction with propellant and cycle

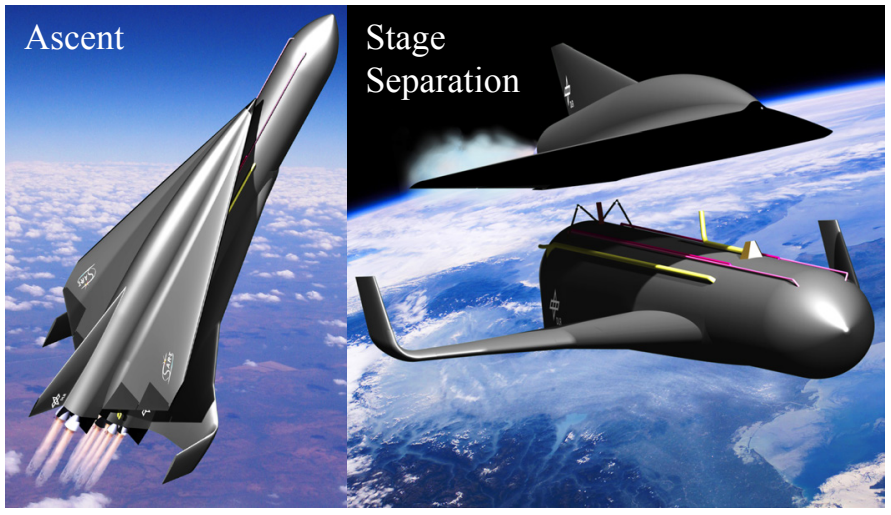

Figure 1. SpaceLiner during ascent and stage separation. commonality also abets using the same engines on both vehicles, thus reducing development and maintenance costs.

Early analyses indicated that significant payload advantages can be realized by the use of propellant crossfeed. The purpose of crossfeeding is to deplete the booster propellants, utilize the combination of booster and orbiter engines during the first stage and have a full tank after staging. The result is an increased mass fraction at the initiation of second-stage operation ${ }^{3}$. However, performance is not the sole driver during the design process of a launch vehicle like the SpaceLiner. Propellant crossfeed technologies are assumed to be extremely complex systems that tend to create design and operational complexity concerns which may overwhelm potential performance gains. In addition, it has to be noted, that no crossfeed system for a configuration like the SpaceLiner has ever been built and therefore careful investigation is required to determine how such a system could be implemented and how complexity issues can be addressed.

The EU-funded project CHATT (Cryogenic Hypersonic Advanced Tank Technologies) has been initiated early 2012 and is part of the European Commission's Seventh Framework Programme (FP7). CHATT focuses on the development of novel cryogenic tank and propellant supply technologies. The tank design of the SpaceLiner is analyzed as well as the design of the feedline system, including the option of crossfeed and the impact of crossfeed on the cryogenic tanks. Different feedline architectures and their potential advantages and disadvantages in terms of system requirements are investigated. The main goal of the studies is to advance and extend the analyses of the propellant supply, including the consideration of potentially critical, transient phases during the ascent of the configuration. In particular, the process of booster separation is a dimensioning factor for the design of the crossfeed system due to the switch of the propellant supply from the booster to the orbiter tanks. The most pressing question is how to achieve constant flow and pressure during separation, since the slightest oscillation can cause critical conditions for the turbopumps due to cavitation and thereby catastrophic failure of the engines in the worst case. While this can be reliably handled for aircraft design, the conditions for rockets are much more extreme: the pressures are extremely high, the flow rates are huge and the engines much more prone to instabilities. To overcome these problems, adequate tank and feedline designs must be found.

\section{Applied Tools}

An overview of the most important tools, which were used during the preliminary design process of the SpaceLiner can be found in Ref. 4. At this point, only the tools, which are utilized for the analysis of the propellant system, are briefly described.

At DLR-SART the in-house tool PMP (Propellant Management Program) was implemented and is currently used for the preliminary design of liquid propulsion systems for launcher and launcher related objects. Currently PMP is reviewed and extended for the assessment of more accurate sizing of the propellant tank pressurization systems for cryogenic launcher stages. Also the option to approximately consider propellant crossfeed is implemented in this context. The basic input data include the propellant masses and types, initial guesses for the tank geometry, materials as well as trajectory- and time-dependent data such as propellant mass flow, engine mixture ratio and acceleration. With this input PMP is capable of approximately calculating the wall thickness, the geometry and the mass of the tanks and the feed-and pressurization lines and also provides the option to consider thermal insulation layers via thermodynamic and structural mechanic formulas. Thermodynamic data are also calculated and given for the different geometry nodes at each time step. Within the present studies, PMP is used for 
the preliminary design of the propellant supply as well as for all steady state calculations of the thermodynamic characteristics.

Since PMP is not capable of simulating transients, a commercial tool is applied there. EcosimPro is a simulation tool developed by Empresarios Agrupados Internacional (EAI) for modeling simple and complex physical processes that can be expressed in terms of differential-algebraic equations or ordinary-differential equations and discrete events. EcosimPro runs on various Windows platforms and uses its own graphic environment for model design. The modeling of physical components is based on the EcosimPro language (EL) which is very similar to other conventional programming languages and is capable to model continuous and discrete processes. EcosimPro employs a set of libraries containing various types of components (mechanical, electrical, pneumatic, hydraulic, etc.) that can be reused to model any type of system. The European Space Propulsion Systems Simulation (ESPSS) contains a set of libraries, purpose-implemented for the analysis and design of space propulsion systems and therefore also for propellant supply. The libraries include different components related to the application fields Combustion, Control, Electrics, Fluids, Mathematics, Mechanics, Tanks, Thermal and Turbo machinery. The original components were designed to simulate transient processes, nevertheless the current ESPSS version also offers the option to conduct steady calculations. ESPSS is widely used, in particular by the ESA, for the design and analysis of space propulsion systems. Regarding to this report, EcosimPro/ESPSS is applied for the simulation of all transient thermodynamic characteristics of the propellant system.

\section{Reference Configuration}

The development of the SpaceLiner concept during the preliminary design phase is described in detail in Ref. 2 and Ref. 5.Within this section, the specifications of the recent reference configuration SpaceLiner 7 (SL7) are given.

\section{A. Shape and Geometry}

The basic arrangement of the tanks with a sample feedline design is shown in Figure 2. Regarding the outer shape the most important geometry parameters for this study are the fuselage diameters and lengths of the orbiter and the booster, because they finally define the available space for the tanks and the propulsion system. In the current reference lay-out, the booster tanks are assumed to be integral tanks, mainly built up of aluminum.

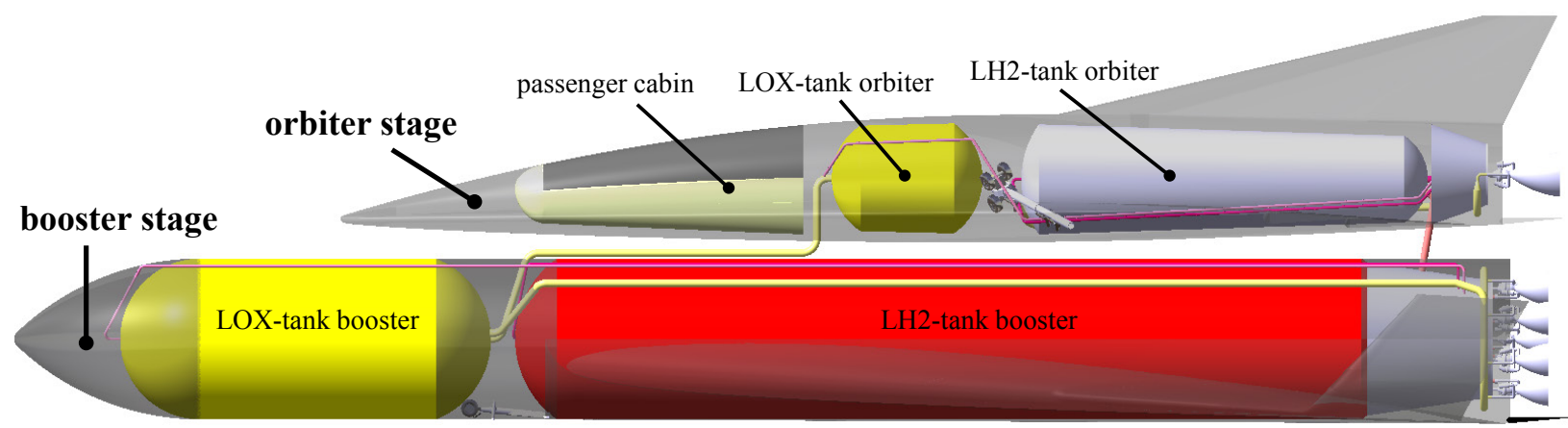

Figure 2. Basic tank configuration of the SpaceLiner.

Figure 3 gives the main geometry parameters for the booster stage.

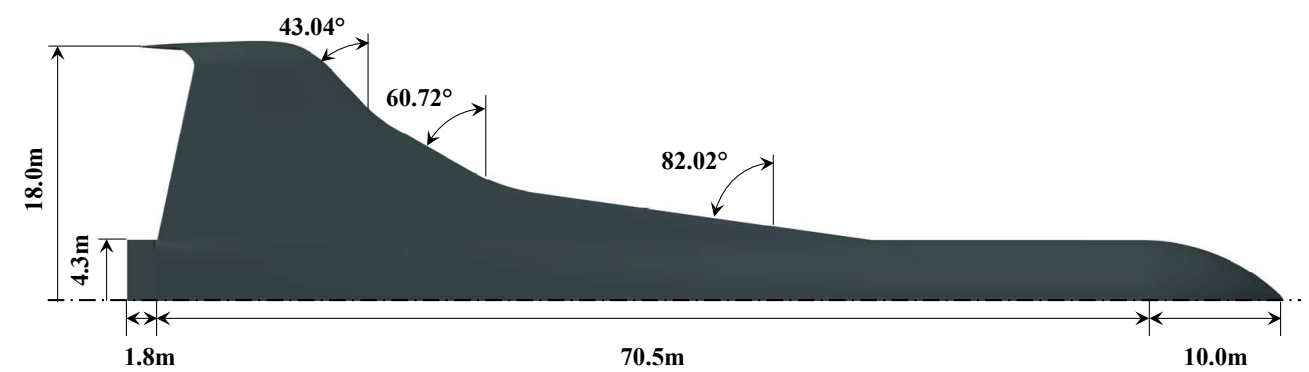

Figure 3. Main dimensions of the SpaceLiner Booster stage. 
The cylindrical fuselage has got a constant diameter of $8.6 \mathrm{~m}$. Figure 4 shows the main geometry parameters of the orbiter stage. In the current reference lay-out the orbiter tanks are assumed to be internal non-integral tanks, made of Carbon Fiber Reinforced Plastic ${ }^{6}$ (CFRP).

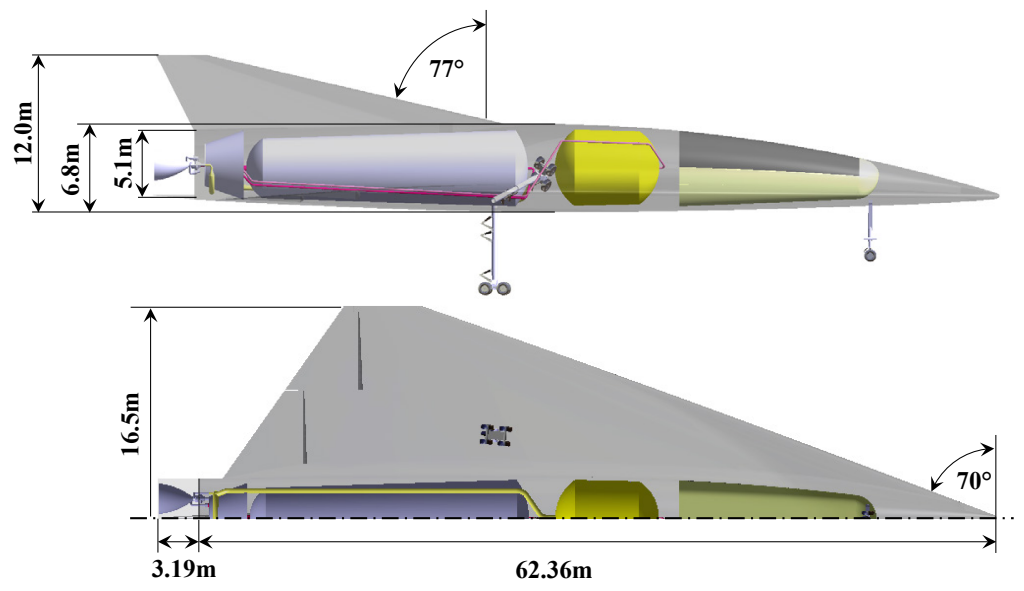

Figure 4. Main dimensions of the SpaceLiner orbiter stage.

More detailed information about the tank geometry data are given in section III-C.

\section{B. Trajectory and Loads}

An important aspect for the design of the propellant system is the target reference trajectory. For the design of the tank structure, the vehicle accelerations and loads must be well known for all occurring flight conditions. Also the total volume of the tanks and thereby the total amount of available propellant strongly affects the achievable MECO velocity. Hence the most recent mission and trajectory data are presented in the following. The nominal SpaceLiner mission can be separated into the following flight phases:

- Boosted vertical ascent of the full configuration (booster + orbiter) until booster MECO and stage separation

- Acceleration of the orbiter stage until orbiter MECO (final altitude, Mach number, $\Delta \mathrm{v}$ )

- Orbiter descent (gliding flight)

- Booster descent (gliding flight)

Figure 5 shows the flight altitude of the SL7 configuration as a function of the flight time for the full nominal flight. The maximum altitude is around $75 \mathrm{~km}$.

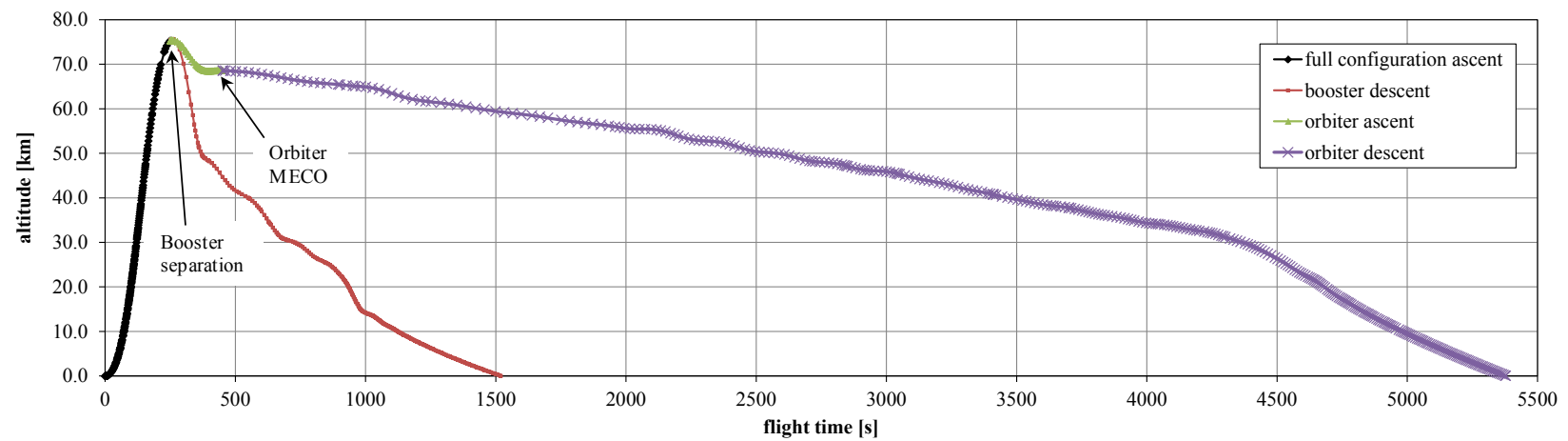

Figure 5. Flight altitude as a function of the time during the nominal SpaceLiner 7 flight.

Figure 6 shows the flight Mach number as a function of the flight time for the full nominal flight. The maximum Mach number is approx. 13 (booster stage) and 24 (orbiter stage). For the design of the feedline system the ascent phases until orbiter MECO are most important. Therefore Figure 7 shows the loads occurring during the boosted ascent of the full configuration until booster separation. 


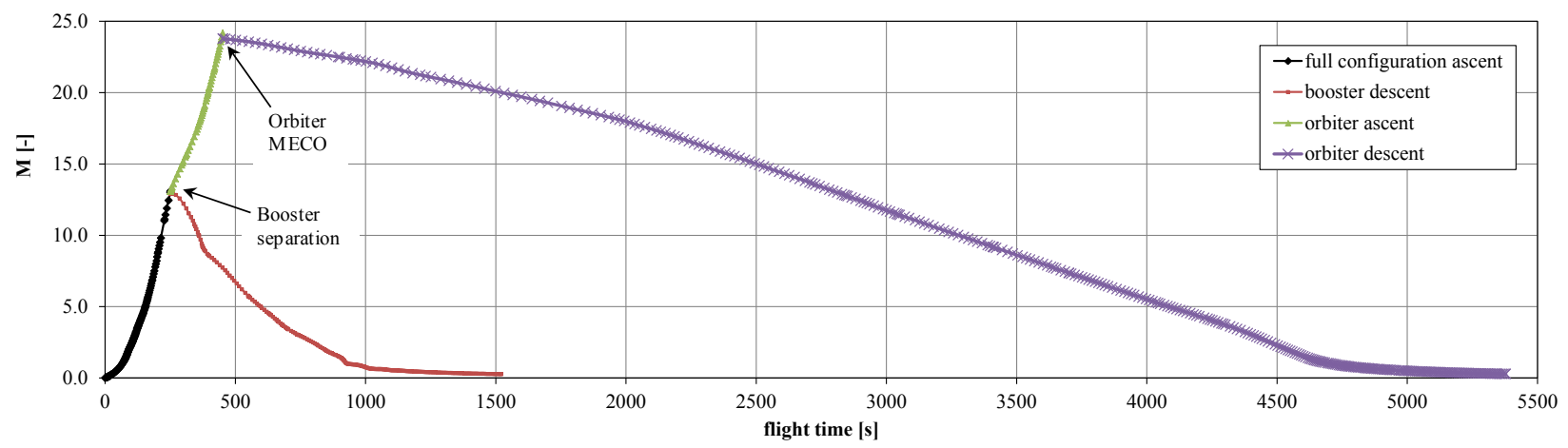

Figure 6. Mach number as a function of the time during the nominal SpaceLiner 7 flight.

A maximum load factor in $\mathrm{x}$-direction of $\mathrm{n}_{\mathrm{x}}=2.5 \mathrm{~g}_{0}$ is not exceeded while the maximum load factor in z-direction $\mathrm{n}_{\mathrm{z}}$ is always below $0.25 \mathrm{~g}_{0}$. It can be noted that the breaks in the gradient are caused by the thrust throttling via stepwise shutdown of the booster engines.

Figure 8 shows the loads for the orbiter ascent from booster separation until MECO. The maximum $n_{z}-10 a d$ is even less than for the full configuration, while a maximum $\mathrm{n}_{\mathrm{x}}$-load of $2.7 \mathrm{~g}_{0}$ is reached. Therefore the maximum value of $2.5 \mathrm{~g}_{0}$, which was set as a requirement in terms of passenger comfort, is exceeded. However, actually this is not a problem because at this point of the trajectory the orbiter engines are shut-down and hence the axial acceleration limit is not exceeded.

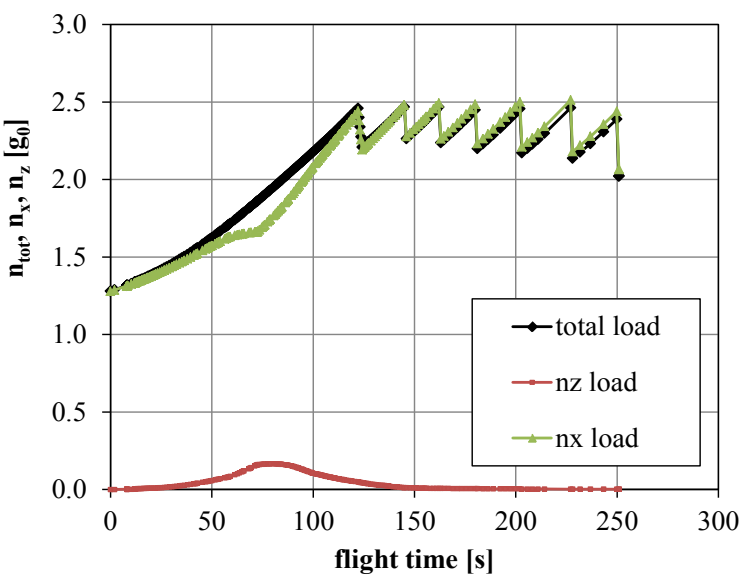

Figure 7. SL7 load factor as a function of the flight time from lift-off until booster separation.

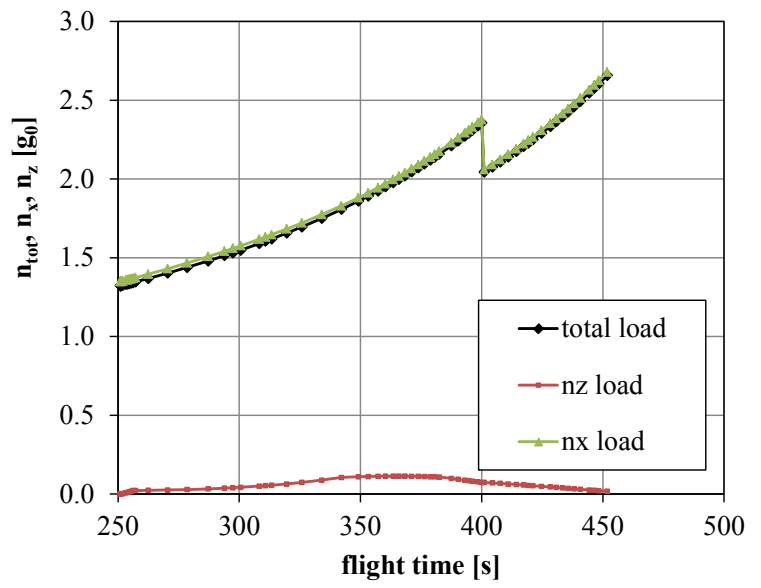

Figure 8. SL7 load factor as a function of the flight time from booster separation until MECO.

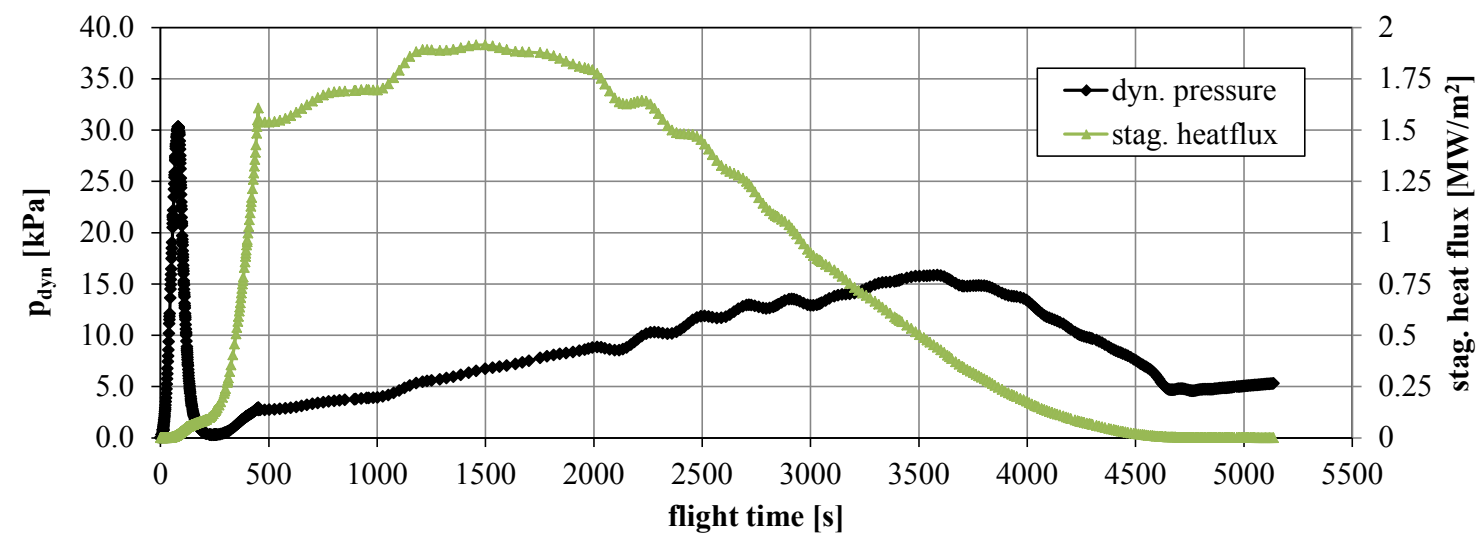

Figure 9. Dynamic pressure and stagnation point heat flux as a function of the flight time for SL7 orbiter. 


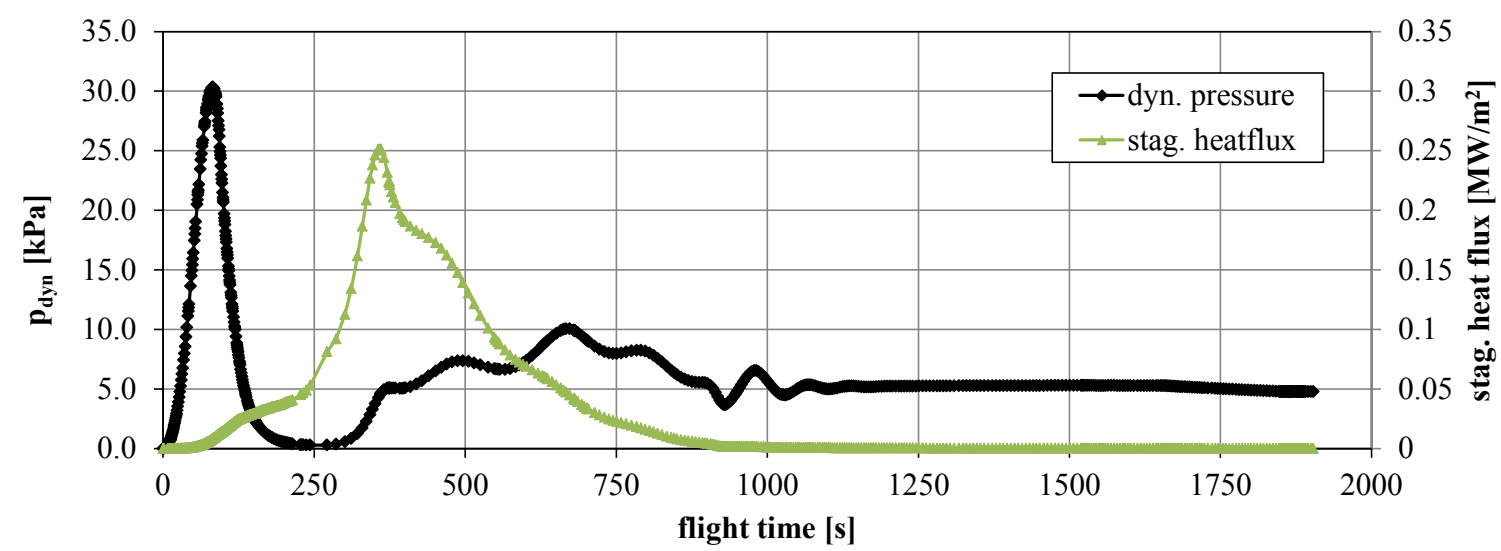

Figure 10. Dynamic pressure and stagnation point heat flux as a function of the flight time for SL7 booster.

Figure 9 and Figure 10 show the stagnation point heat fluxes and the dynamic pressures along the full orbiter and booster trajectory as a function of the flight time. The heat loads must be considered for the SL7 design because they have an impact on the passive thermal protection system of the configuration and also on the cryo-insulation.

\section{Preliminary Tank Design}

Table 1 gives an overview of the required propellant masses, which must be stored in the tanks. Furthermore the propellant volumes and the total internal tank volumes are given. There is a difference between both due to the ullage volume required by pressurization gas and the volume of internal tank structures. The ratio of the propellant volume and the total tank volume can therefore be described by a volume reduction factor, which is also given in Table 1.

\begin{tabular}{l|cccc}
\hline \multicolumn{1}{l}{} & $\begin{array}{c}\text { propellant } \\
\text { mass [kg] }\end{array}$ & $\begin{array}{c}\text { propellant } \\
\text { volume }\left[\mathrm{m}^{3}\right]\end{array}$ & $\begin{array}{c}\text { int. tank } \\
\text { volume }\left[\mathrm{m}^{3}\right]\end{array}$ & $\begin{array}{c}\text { volume red. } \\
\text { factor [-] }\end{array}$ \\
\hline Booster LOX & 1099524 & $962.7^{*}$ & 992.3 & 0.970 \\
Booster LH2 & 180250 & $2542.7^{* *}$ & 2577.5 & 0.987 \\
Orbiter LOX & 187448 & $164.1^{*}$ & 171.1 & 0.959 \\
Orbiter LH2 & 30729 & $433.5^{* *}$ & 446.4 & 0.971 \\
\hline$* 90.00 \mathrm{~K}$, density $1142.11 \mathrm{~kg} / \mathrm{m}^{3}$ & $* * 20.20 \mathrm{~K}$, density $70.89 \mathrm{~kg} / \mathrm{m}^{3}$ & \\
\hline
\end{tabular}

Table 1. SpaceLiner 7 major tank data.

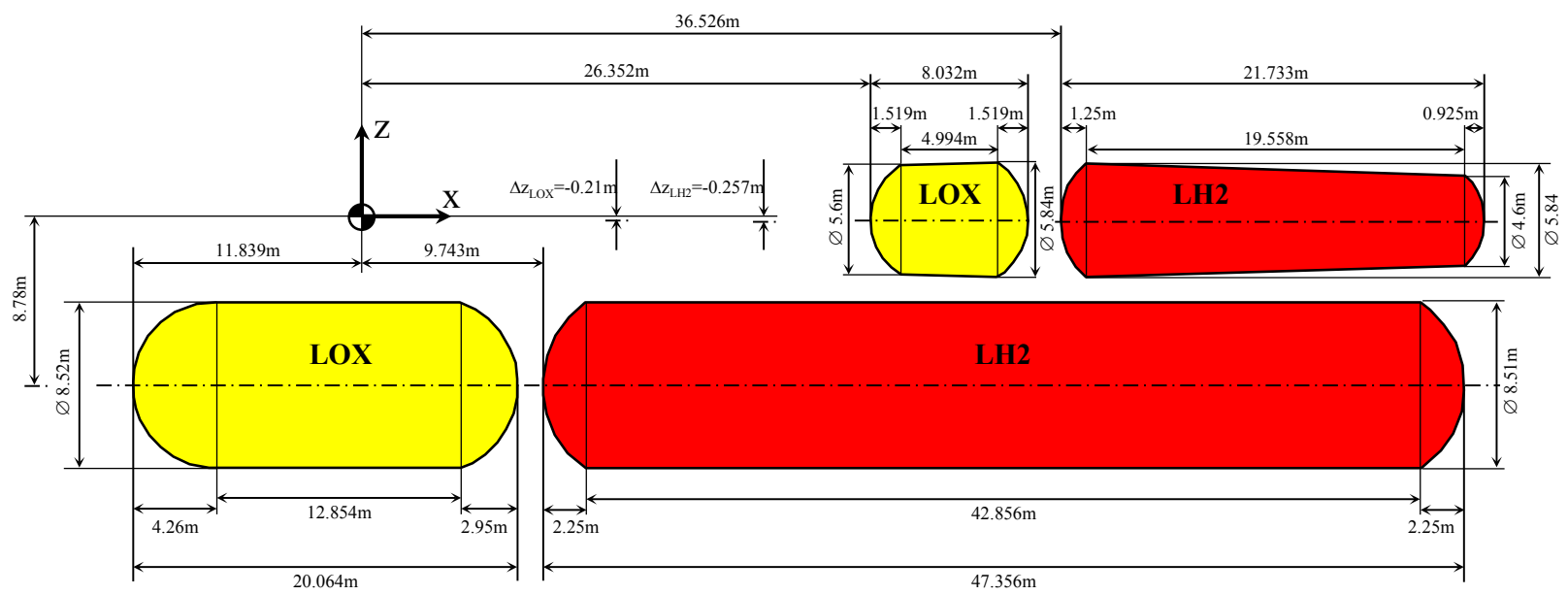

Figure 11. SL7 main internal tank dimensions.

6

American Institute of Aeronautics and Astronautics 
The main tank dimensions are shown in Figure 11. The data were generated by PMP considering the amount of propellant required to fulfill the reference mission. PMP also provides output data for the tank wall and insulation layer thickness. However, as these layers are merged with the high-temperature TPS to some extent, only the internal dimensions are given here. It can already be noted here that during the vertical ascent of the vehicle, the forward position of the LOX-tanks causes high hydraulic heads, which can be beneficial for the propellant transport to the engines.

\section{SpaceLiner Main Engines (SLME)}

Similar staged combustion cycle rocket engines with a moderate chamber pressure have been selected as the baseline propulsion system both for the booster and passenger stage. The desired engine performance data are not overly ambitious and have already been exceeded by existing engines like $\mathrm{SSME}^{7}$.

However, the ambitious goal of a passenger rocket is to considerably enhance reliability and reusability of the engines beyond the current state of the art. The expansion ratios of the booster and orbiter engines are adapted to their respective optimums; while the mass flow, turbo-machinery, and combustion chamber are assumed to remain identical in the baseline configuration.

Figure 12 and Figure 13 demonstrate the significantly different sizes of the booster and orbiter engines with similar combustion chamber,

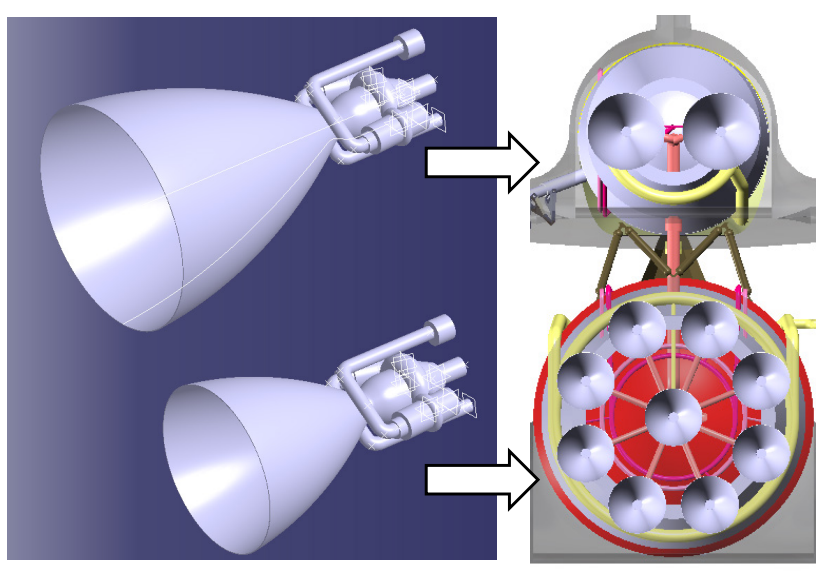

Figure 12. CAD geometry and arrangement of orbiter and booster engines.

turbomachinery, and manifolds. The expansion ratio $\varepsilon$ is defined by the ratio of the cross section areas at the nozzle exit and the nozzle throat. Preliminary analyses of the turbomachinery confirm the overall feasibility of the design and show some efficiency improvement potential when comparing NASA empirical data to the assumptions used in the cycle analyses. The masses per engine are estimated at $3375 \mathrm{~kg}$ with large nozzle for the passenger stage ( 2 engines) and at $3096 \mathrm{~kg}$ for the booster stage (9 engines).

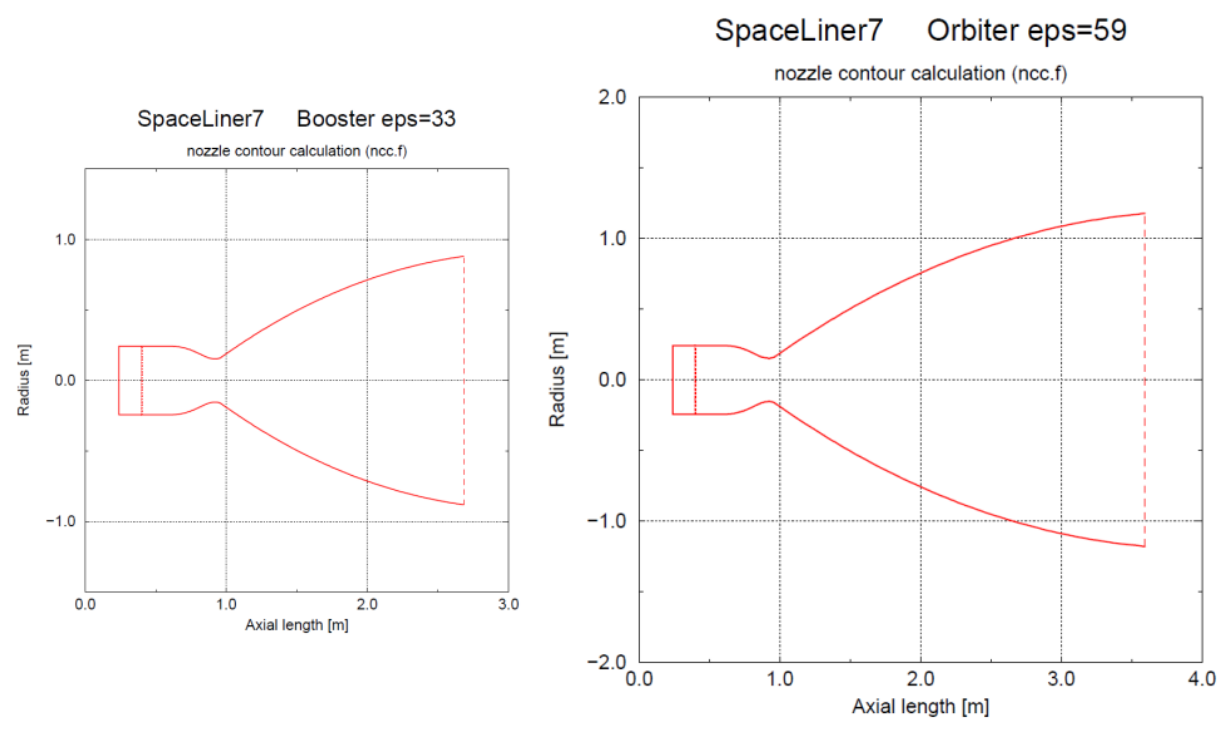

Figure 13. Internal contour of SpaceLiner 7 main engine ( $\varepsilon=33$ booster, $\varepsilon=59$ orbiter).

A mixture ratio of 6 is a typical selection in a high performance LOX-LH2 rocket engine and has already been used for the SSME. However, the optimum engine mixture ratio is always mission-dependent. Furthermore, adaptation of the mixture ratio during flight might improve performance with better $\mathrm{I}_{\mathrm{sp}}$ and improved thrust levels. Previous analyses have already shown, that the vacuum $I_{\text {sp }}$ for the booster engines as well as for the orbiter engines increases with decreasing mixture ratio whereas the sea level $\mathrm{I}_{\mathrm{sp}}$ increases with increasing mixture ratio. However, 
also a non-negligible impact of mixture ratio variations on the required turbomachinery power has to be stated, if the chamber pressure is also changing as for the SpaceLiner engine. Therefore, for further analyses the mixture ratio has been limited in the range 5.5 to 6.5 to keep subcomponent (e.g. turbomachinery, pre-burner) demands within reasonable boundaries. Therefore the engines are running with a higher mixture ratio at lift-off and switching later into flight to the lower mixture ratio. The mixture ratio switch would also serve as a first step in throttling when it is anyhow required to keep acceleration levels for the passengers at a comfortable maximum of $2.5 \mathrm{~g}$. The best mixture ratio of the SpaceLiner main propulsion system along its mission has been defined by system analyses optimizing the full nominal trajectory. After completion of the trajectory optimization, the obtained mission average tank mixture ratio in orbiter and booster remains very close to 6.0. For the most recent trajectory the orbiter engine mixture ratio is 6.5 up to a flight time of about $400 \mathrm{~s}$ and then switched to 5.5 .

\begin{tabular}{l|ccc|ccc}
\hline & \multicolumn{3}{|c|}{ Booster } & \multicolumn{3}{c}{ Orbiter } \\
\hline Mixture ratio [-] & 5.5 & 6.0 & 6.5 & 5.5 & 6.0 & 6.5 \\
\hline Chamber pressure [MPa] & 15.1 & 16.0 & 16.9 & 15.1 & 16.0 & 16.9 \\
\hline Fuel-rich preburner pressure [MPa] & 29.4 & 30.0 & 30.8 & 29.5 & 30.2 & 31.0 \\
\hline Oxidizer-rich preburner pressure [MPa] & 29.1 & 29.7 & 30.5 & 29.2 & 29.9 & 30.7 \\
\hline Fuel-rich preburner temperature [K] & 732 & 735 & 738 & 720 & 722 & 724 \\
\hline Oxidizer-rich preburner temperature [K] & 773 & 775 & 778 & 772 & 774 & 777 \\
\hline Mass flow per engine [kg/s] & 481 & 517 & 555 & 481 & 518 & 555 \\
\hline Expansion ratio [-] & 33 & 33 & 33 & 59 & 59 & 59 \\
\hline Specific impulse in vacuum [s] & 439 & 437 & 435 & 451 & 449 & 448 \\
\hline Specific impulse at sea level [s] & 387 & 389 & 390 & 357 & 363 & 367 \\
\hline Thrust in vacuum per engine [kN] & 2061 & 2206 & 2356 & 2116 & 2268 & 2425 \\
\hline Thrust at sea level per engine[kN] & 1817 & 1961 & 2111 & 1678 & 1830 & 1986 \\
\hline
\end{tabular}

Table 2. SpaceLiner Main Engine (SLME) technical data.

Table 2 gives an overview about all major SLME engine operation data for the nominal mixture ratio range as obtained by cycle analyses. Internal conditions were calculated with a general assumption of $70 \%$ efficiency of all turbomachinery. Later analyses of the turbopumps show that better efficiencies are reachable which could allow for reduced pressures or temperatures inside the engine. This might improve lifetime of components. Overall engine performance is not affected by these efficiencies because the SLME is a closed staged combustion cycle. More detailed information about the SLME can be found in Ref. 8.

\section{Propellant Crossfeed}

A literature research was conducted in order to identify particular advantages, disadvantages, problems and challenges of propellant crossfeed system as well as to get some idea for potential promising solutions for system architectures. The results are presented within this section. First, an overview of the different references and their activities and general issues regarding to propellant crossfeed is given. Afterwards the main types of crossfeed architectures are explained and technical details and design objectives and guidelines such as the selection of proper valves are discussed with respect to the SpaceLiner configuration and modeling.

\section{A. Activities and Issues Related to Crossfeed}

Smith and Philips ${ }^{9}$ compared three dominant Two Stage To Orbit (TSTO) class architectures, considering the equivalent mission and payload requirements: Series Burn (SB) Parallel Burn with crossfeed (PBw/cf) and Parallel Burn, no-crossfeed (PBncf). It was found out, that for LOX/LH2 the PBncf architecture can achieve a mass growth of up to $20 \%$ compared to PBw/cf. Regarding to SB one of the main issues is the risk from malfunctions during air start of the orbiter engines, which is generally avoided for parallel burn configurations. PBw/cf allows the lightest possible dry mass in cases, where the orbiter and booster use the same propellants (e.g. SpaceLiner) but adds the complexity of the crossfeed system. The major issue is here the design difficulty and cost risk inherent in making a system that is doubly or triply redundant with a reliability of $99.9 \%$ or higher, such as it is definitely necessary for the SpaceLiner. The PBncf architecture avoids the complexity of a crossfeed system at the cost of a larger booster and orbiter. The major complication in dealing with PBncf vehicles is that the orbiter consumes $25 \%-35 \%$ of its propellant before staging. The orbiter's propellant usage during the boost phase can be minimized by either using smaller engines or by throttling the orbiter engines as deeply as possible. Using some combination of these methods 
was found to allow the lowest possible orbiter boost phase propellant consumption. The potential disadvantage of smaller engines is the increased $\Delta \mathrm{v}$-loss due to the longer ascent time. Furthermore different thrust-to-weight ratios $\mathrm{T} / \mathrm{W}$ between booster and orbiter will cause a Center of Gravity $(\mathrm{CoG})$ control problem, which must be countered with thrust vectoring gimbal angles resulting in significant launch pad drift. During the ascent this problem will become more severe as the booster uses all of its propellant. Thus the vehicle and in particular the wings might suffer substantial structural loads if it cannot maintain $0^{\circ}$ angle of attack while it passes through the maximum dynamic pressure. Use of throttling engines allows better $\mathrm{CoG}$ control if the orbiter engines are kept at near nominal throttle at the beginning of the launch and are deep throttled afterwards to save orbiter propellant. The possible drawback of deep throttling is the impact on reliability of additional throttling events due to the possibility of engine failure while throttling.

Stanley et al. ${ }^{10}$ conducted conceptual design studies for the fully reusable Advanced Manned Launch System (AMLS), a potential replacement of the Space Shuttle. They found improvement in gross weight of $25.6 \%$ and in dry weight of $22.6 \%$ by using crossfeed. Sosa et al. performed studies about the design and integration of a cryogenic propellant crossfeed system for the AMLS ${ }^{11}$. The analysis efforts were concentrated on the LOX system due to the greater concern for surge with LOX. For leakage and seal design concerns, the efforts were directed to the LH2 systems. Engine conditioning was not addressed. In detail the following steps were conducted:

1) Development of guidelines and design objectives for the selection of a "large internal diameter (I/D) inflight separable" disconnect set. Costs were discussed.

2) Assessment and integration of the crossfeed system and the loading/draining, venting and pressurization processes.

3) Analysis was performed in system definition, flow-rate evaluations for line sizing, for staging crossfeed transient performance evaluation and propellant depletion.

There are lots of similarities between the AMLS and the SpaceLiner configuration and the studies conducted in Ref. 11 coincide to a large extent to what shall be investigated for the SpaceLiner crossfeed in CHATT. Even if the results cannot be directly applied to the SpaceLiner, the AMLS offers useful information for how to run propellant feedlines between two separate stages.

Chandler et al. conducted experimental and numerical analyses of Main Propulsion System (MPS) LOX/LH2 crossfeed for a next generation Reusable Launch Vehicle (RLV) and stated, that crossfeed between the booster and the orbiter stages could reduce the TSTO vehicle weight and Design, Development, Test and Evaluation (DDT\&E) costs by approx. $25 \%$ while increasing safety and reliability ${ }^{12}$. In the framework of the TA-8 Propulsion Risk Reduction MPS Crossfeed Project extensive studies were performed, including the experimental MPS crossfeed water demonstration test program, which addresses all activities required to reduce the risks for the MPS crossfeed system from Technology Readiness Level (TRL) 2 to TRL 4. The top-level objectives of the water flow test were:

4) To validate the passive crossfeed system through test and verify the crossfeed system's ability to transition propellant flow from a booster tank to an orbiter tank

5) To provide test data for CFD and flow transient model validation. These models can then be used for full scale design and analysis

6) To obtain test data using a 4" subscale crossfeed valve that can be used for the development of a full-scale or near full-scale crossfeed valve

7) To increase the crossfeed technology readiness level to 4

8) To gain operational experience with a test article that can later be used in a cryogenic liquid experiment with liquid nitrogen and liquid oxygen

Therefore technical solutions to properly terminate the flow between both stages were discussed and parametric studies related to the flow properties in the lines during the separation process were carried out. A transient, onedimensional system simulation was developed for the subscale crossfeed water flow tests. To ensure accurate representation of the crossfeed valve dynamics in the system model, a hi-fidelity, three-dimensional CFD model was employed $^{13}$. The results from this model were used for the specification of the valve's flow characteristics in the system simulation. This yielded a crossfeed system model, which was anchored to the specific valve hardware and achieved good agreement with the measured test data. These results allowed the transient models to be correlated and validated and used for full scale mission predictions. The full scale model simulations indicated crossfeed to be viable with the system pressure disturbances at the crossfeed transition being less than experienced by the propulsion system during engine start and shutdown transients. In the framework of the same project Nguyen et al. 
concentrated on the development of a pressurization system model which was validated by means of the crossfeed subscale water test article ${ }^{14}$ and then applied for the simulation of a generic bimese TSTO RLV ${ }^{15}$. The implemented model showed an excellent agreement with the test data. Within these references also an operation sequence is given for the TSTO RLV, which might be also interesting for the separation process of the SpaceLiner, even if the absolute times are not the same.

Potential crossfeed technologies for the National Launch System (NLS) were discussed by Gormley and Vaddey for a heavy-lift launcher, composed of two booster stages and one core stage in parallel alignment ${ }^{3}$. The approach taken in this study was to evaluate different propellant transfer system architectures for LOX/LH2 and identify the relative benefits and drawbacks associated with each concept. Within each architecture category, several transfer mechanisms were evaluated. As a conclusion of the work, a summary table with the pros and cons of each system is given. This table can also be taken as a baseline for the assessment of potential solutions for the SpaceLiner. It was found, that liquid propellant launch vehicles can satisfy heavy-lift payload requirements by crossfeeding propellants from the booster tanks to the orbiter engines during first stage. Two crossfeed systems were identified that minimize design and operational complexity and maximize performance. However, the investigation of the different concepts in Ref. 3 is of rather simple and general character and does not go too much into technical detail.

As cavitation is generally one of the most critical issues for the design of propellant feed systems, Mehta et al. described development work on cavitation prediction and prevention and its implications on cryogenic propellant feed system design ${ }^{16}$. Cryogenic feed system cavitation usually manifests itself when the liquid in the propellant tank is at saturated or near saturated conditions. On the one hand these conditions might be critical for the turbopumps. On the other hand such conditions can be allowed to occur intentionally in a launch vehicle to enhance payload capability by permitting lower ullage pressure in order to decrease pressurization system and tank structural masses.

Stinson et al. performed a series of experimental liquid hydrogen turbopump tests to demonstrate the feasibility of zero-tank net positive suction head (NPSH), which is the difference between the hydraulic head at a certain point and the vaporization head of the fluid ${ }^{17}$. Respectively the net positive suction pressure (NPSP) is the difference between the pressure at a certain point and the fluid's vaporization pressure at that point and therefore both, the NPSH and the NPSP are critical parameters for cavitation. A J-2 engine hydrogen pump and S-IVB stage fuel system were used for the investigation. The pump was operated at flows and speeds equivalent to normal J-2 engine operating conditions. These tests showed zero-tank NPSH to be a realistic operating mode that should be considered for future applications.

Jenkins gave some basic information about the crossfeed system of the Space Shuttle, in particular schematic descriptions of the separation valve, which are mentioned later within this report ${ }^{7}$.

An analytical and experimental study of liquid rocket propellant feedline dynamics has been performed by Holster $^{18}$. The frequency responses of various line configurations tested were compared with the computed theoretical results.

Within FESTIP, a variety of different fully reusable launch vehicles is examined using the same mission scenario requirements and design standards to enable comparison of the vehicles. In this project, propellant crossfeed was investigated for the FSS-9 vehicle, a parallel TSTO-R-VTHL launcher ${ }^{19}$. Compared to an accordant Single Stage To Orbit vehicle, mass savings of approx. $30 \%$ were found but, nevertheless, higher total life cycle costs were determined utilizing crossfeed. This is mainly driven by the two vehicles to be developed and manufactured and the assumed additional operational effort due to the operation of two stages.

Propellant crossfeed for LOX/LH2 was also discussed in the framework of the EVEREST configuration studies. A very short overview of three different cross-feed architectures for a TSTO vehicle is given in Ref. 20. The different architectures and their particular issues are mentioned in the following.

\section{B. Crossfeed Architectures}

There are three main options of crossfeed for which to have the orbiter engines consume propellant stored in the booster tanks before separation so that the orbiter tanks remain full:

- Line-to-line

- Tank-to-tank

- Tank-to-buffer-tank

The schemes of the general architectures are shown in Figure 14 and described in the following. 


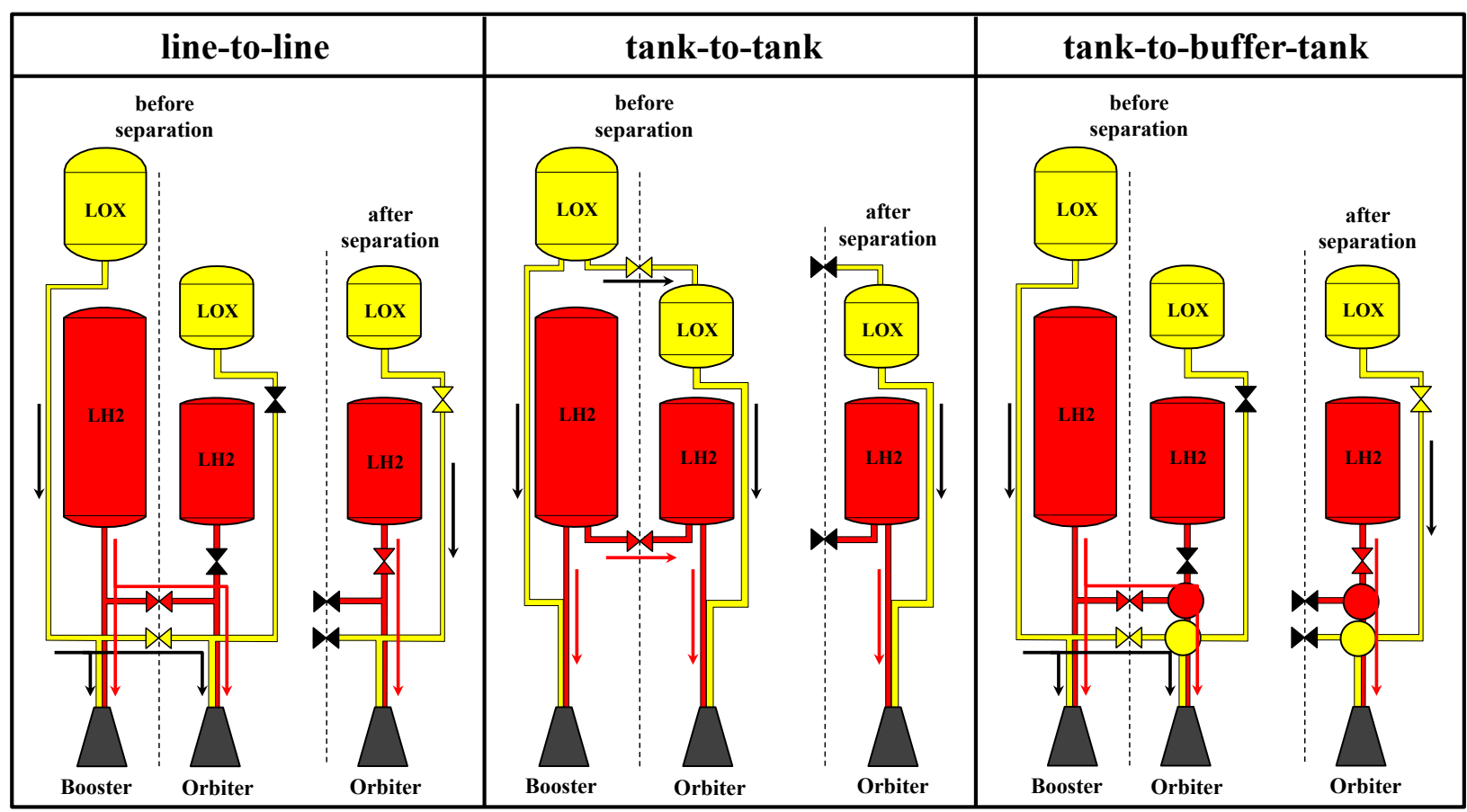

Figure 14. Main types of crossfeed architectures.

\section{Line-to-line}

In the line-to-line configuration, the orbiter engines are fed directly from the booster tanks before separation and then afterwards by the orbiter tanks. A regulation valve is used to switch between the feedlines from the booster and the feedlines from the orbiter during separation so that a constant flow of propellant to the engines is maintained. This is theoretically the simplest system, because the only difference between this system and a normal feed system is the regulation valve to switch lines. In theory, this should certainly be possible since aircraft have a system to switch tanks mid-flight. However, there are several complications that arise.

The most pressing question is how to achieve constant flow during separation, since the slightest oscillation can cause critical conditions for the turbopumps which, in the worst case, result in catastrophic failure of the engines. While this has been achieved in aircraft, the conditions for rockets are much more extreme: the pressures are extremely high, the flow rates are huge and the engines much more prone to instabilities. Therefore, while the design of this system is in theory simple, since it has never been done, it must be given significant attention.

The other big question for the SpaceLiner is whether leaving the propellant in the orbiter tanks just sitting there until separation is a problem due to the heat fluxes and propellant stratification, especially for the LH2 tank. Due to the high heat fluxes from the outside into the tank, the temperature of the propellant increases over time. As a result, over the time until separation, there will be a large amount of vaporization and stratification within the orbiter tanks, with more acute effects in the LH2 tank. As the propellant vaporizes, the pressure in the tank builds up, and so the tank must constantly be vented in order to keep the ullage pressure at the desired level. This is a waste of propellant that could cause problems in a system as sensitive to mass as the SpaceLiner. Additionally, due to stratification, it is possible that over the course of the booster and then orbiter burns, the temperature of the orbiter propellant may rise above the temperature that the engines can handle, resulting in system failure. These issues can possibly be avoided by increasing the ullage volume and increasing the tank insulation, but these have effects on the total system mass that must be taken into consideration.

Other issues involved are the need to prevent backflow as the orbiter flow begins, the need to make sure the conditions of the booster flow at the end of its burn match the conditions of the orbiter flow right at staging, and the potential issue of having unused propellant sitting in the part of the crossfeedline from the booster that resides in the orbiter but is not used after separation.

\section{Tank-to-tank}

In the tank-to-tank configuration, the booster tanks feed propellant directly to the orbiter tanks before separation, keeping them full while they fuel the orbiter engines. The advantage of this system is that the engines are always fed 
from the same tank and so maintaining an almost constant flow rate over the entire burn of the orbiter, especially during separation, should be much simpler. The other advantage of this system is that it avoids the issues arising from heat fluxes and stratification in the line-to-line approach. It can be mentioned, that the crossfeed line and the disconnect and check valves may be designed principally similar to the line-to-line architecture. However, this system also has its questions, the main one being how to push propellant from one tank to another.

Two different propellant transfer methods are investigated for tank-to-tank architecture in Ref. 3, both with the LOX tanks in forward position - similar to the current SpaceLiner arrangement. The two discussed mechanisms are pump transfer and pressurized transfer.

The use of pumps to transfer propellant from the booster to the orbiter introduces design feasibility issues associated with the pump's broad duty cycle because of variable head rise as the booster propellant is consumed, changes in vehicle acceleration and constant propellant flow rate. The evaluation has shown that the pump design and development is the most challenging task. It was found that no pump has ever been designed that satisfies the requirements generated for the crossfeed application in terms of power, specific speed and head coefficient. Additionally to the design issue, an adequate net positive suction pressure (NPSP) is required for efficient work of the pumps. This becomes difficult towards staging since the booster propellant levels are low (filling level, acceleration). Solving this problem by stopping the pumps before depletion of the booster tanks will reduce the performance advantage of crossfeed. Integration of a pump transfer system is further complex by the control logic needed to properly and efficiently run the pumps, responding to acceleration changing head differential, orbiter and booster ullage pressures and pump performance. Due to all these issues the pump transfer is assessed to be prohibitive for use in a flight crossfeed system in Ref. 3.

Problems associated with the pump design and operation can be eliminated by the use of a high booster ullage pressure to transfer propellant to the orbiter tanks. In design of a pressure-fed transfer system, the booster ullage pressure must vary to adjust to the changing head differential and vehicle acceleration. The booster tank ullage pressures supplied by pressurization gas from the engines must be sufficient to overcome the hydrostatic head differential between the core and booster tanks. Further, this differential is amplified by the instantaneous vehicle thrust acceleration. Since the vehicle's acceleration is continuously changing during ascent, the instantaneous head differential will fluctuate during flight. The net affect of these parameters is to increase the performance requirements from the vehicle pressurization system. A complex control logic system is required to ensure the transfer system operates efficiently. In addition, an active pressurization that can quickly adjust to changing ullage pressure needs is required. Impact to propellant tank structural weight as a result of the increased ullage pressure is considered a critical driver for the pressurized transfer option. The structural weight increase is affected primarily by the maximum ullage pressure required.

Nevertheless the pressurized transfer seems less critical for the SpaceLiner, at least for the transfer of LOX due to the beneficial head difference of the tanks.

Another question is how flow from the booster tanks to the orbiter tanks will affect the dynamics inside the orbiter tanks. This is something that has not been analyzed yet and will also require careful consideration before the implementation of this system.

\section{Tank-to-buffer-tank}

This design can be considered as a trade-off between line-to-line and tank-to-tank architecture to avoid the disadvantages of both. Until separation the buffer tanks in the orbiter are fed by the crossfeed lines coming from the booster tanks. After staging they are then fed by the feedlines of the orbiter tanks. This solution should minimize the problem of line pressure fluctuations during stage separation, but demands the addition of relatively large and heavy tanks. The previously mentioned problem of pressure rise and propellant stratification, which might occur for lineto-line configuration, remains also for this solution. During the analyses it was found that this option is not attractive for the SpaceLiner and will therefore not be further considered here.

\section{Steady Simulations}

The main goal of these preliminary analyses is to determine what size of feedlines and tank pressure is required to maintain the proper Net Positive Suction Pressure (NPSP) at the entrance to the turbopumps in order to prevent cavitation. NPSP is the difference between the pressure and the vaporization pressure of the fluid. If the NPSP is too low when the fluid enters the pumps, vaporization and the formation of bubbles could begin at the blades of the pump, an event known as cavitation. This can cause the pump to fail and be destroyed in the worst case.

The first step was to determine the minimum NPSP allowable for the SpaceLiner system. The minimum required NPSP is strongly dependent on the particular turbopump, the optional inducer and the propellant system 
configuration and therefore the literature references are not always in full accordance with each other. Hence, the question which value should be assumed as minimum required NPSP for the SpaceLiner turbopumps cannot be answered easily. In general, low complexity of the turbopump system means lower turbopump mass but also higher required NPSP and therefore higher mass of the remaining propellant system, whereas high complexity of the turbopump system results in contrary issues. Investigation into the Saturn V J-2 systems suggested that typical requirements were a minimum of $230 \mathrm{kPa}$ NPSP for LOX and 70kPa NPSP for LH2. Because earlier analyses of the propellant supply and also the investigation of the SLME was conducted assuming a minimum NPSP of 70kPa for LH2 and $230 \mathrm{kPa}$ for LOX, these values are adopted for the analyses presented within this report. Based on the statements which were found in the literature, it can be expected that broad margins are included in these values.

The steady simulations were performed with the DLR in-house tool PMP. Because dynamic behavior cannot be considered and the modeling in PMP is rather simple, these studies are not very suitable to make a final decision for a particular crossfeed architecture or even a detailed crossfeed-line component design, but rather for the preliminary dimensioning of pipe and tank geometry and pressurization for the adherence of minimum NPSP.

PMP automatically sizes the tanks, but the feedlines must be created by the user. Bellows, pipebends, and other elements are inserted by the user and the program calculates the pressure drop accordingly. There are two valves between the tanks and the engines: one at the end of the main feedline in front of the engine distribution lines, with a pressure drop of 20,000 $\mathrm{Pa}$, and one at the end of each engine distribution line in front of the engines, with a pressure drop of 10,000 $\mathrm{Pa}$. The location of the feedlines is designed to remain inside the SpaceLiner and avoid the landing gear and other compartments.

The crossfeed lines between the booster and the orbiter are simple models to give estimates of pressure, NPSP, masses, and locations of the lines. PMP cannot handle transients, so the transition at separation from the crossfeed lines to the orbiter main lines is instantaneous. Within this section the line-to-line architecture is investigated first due to its relative simplicity.

\section{A. Line-to-Line}

In the framework of CHATT, a potential design of a line-to-line architecture was developed. In this design the crossfeed lines are branching lines from the booster feedlines to the orbiter feedlines. The configuration architecture, as it is modeled in PMP, is shown in Figure 15.

Table 3 gives an overview of the feedline geometry and mass data of the updated architecture. It must be noted, that the diameter of the LOX orbiter engine distribution lines is increased from $0.15 \mathrm{~m}$ to $0.3 \mathrm{~m}$, because it was found that there are large pressure losses and very high flow velocities in these lines. For the same reason the booster engine distribution line diameter is increased from $0.135 \mathrm{~m}$ to $0.2 \mathrm{~m}$ (LOX) and from $0.19 \mathrm{~m}$ to $0.25 \mathrm{~m}$ (LH2). Furthermore it was found that an insolation thickness of $10 \mathrm{~mm}$ is sufficient for the LH2 crossfeed line.

\begin{tabular}{c|c|c|c|c|c|c|c}
\hline Line & $\begin{array}{c}\text { Number } \\
\text { of lines }\end{array}$ & $\begin{array}{c}\text { Internal } \\
\text { diameter }\end{array}$ & $\begin{array}{c}\text { Total } \\
\text { length }\end{array}$ & $\begin{array}{c}\text { Internal } \\
\text { volume }\end{array}$ & $\begin{array}{c}\text { Struct. } \\
\text { thickness }\end{array}$ & $\begin{array}{c}\text { Insolation } \\
\text { thickness }\end{array}$ & $\begin{array}{c}\text { Total } \\
\text { mass }\end{array}$ \\
\hline LOX-B & 2 & $0.4 \mathrm{~m}$ & $83.88 \mathrm{~m}$ & $8.47 \mathrm{~m}^{3}$ & $2.5-3.4 \mathrm{~mm}$ & $10.0 \mathrm{~mm}$ & $1180.8 \mathrm{~kg}$ \\
\hline LOX-O & 1 & $0.4 \mathrm{~m}$ & $32.20 \mathrm{~m}$ & $3.54 \mathrm{~m}^{3}$ & $2.5 \mathrm{~mm}$ & $10.0 \mathrm{~mm}$ & $425.2 \mathrm{~kg}$ \\
\hline LH2-B & 1 & $0.5 \mathrm{~m}$ & $4.1 \mathrm{~m}$ & $0.81 \mathrm{~m}^{3}$ & $2.5 \mathrm{~mm}$ & $10.0 \mathrm{~mm}$ & $112.4 \mathrm{~kg}$ \\
\hline LH2-O & 1 & $0.4 \mathrm{~m}$ & $2.0 \mathrm{~m}$ & $0.25 \mathrm{~m}^{3}$ & $2.5 \mathrm{~mm}$ & $10.0 \mathrm{~mm}$ & $234.7 \mathrm{~kg}$ \\
\hline LOX-C & 1 & $0.4 \mathrm{~m}$ & $21.44 \mathrm{~m}$ & $2.42 \mathrm{~m}^{3}$ & $2.5 \mathrm{~mm}$ & $10.0 \mathrm{~mm}$ & $493.9 \mathrm{~kg}$ \\
\hline LH2-C & 1 & $0.4 \mathrm{~m}$ & $9.41 \mathrm{~m}$ & $1.08 \mathrm{~m}^{3}$ & $2.5 \mathrm{~mm}$ & $10.0 \mathrm{~mm}$ & $152.7 \mathrm{~kg}$ \\
\hline LOX-BE & 9 & $0.2 \mathrm{~m}$ & $0.68 \mathrm{~m}$ & $0.005 \mathrm{~m}^{3}$ & $8.5 \mathrm{~mm}$ & $10.0 \mathrm{~mm}$ & $31.2 \mathrm{~kg}$ \\
\hline LH2-BE & 9 & $0.25 \mathrm{~m}$ & $3.61 \mathrm{~m}$ & $0.163 \mathrm{~m}^{3}$ & $2.5 \mathrm{~mm}$ & $10.0 \mathrm{~mm}$ & $44.5 \mathrm{~kg}$ \\
\hline LOX-OE & 2 & $0.3 \mathrm{~m}$ & $0.84 \mathrm{~m}$ & $0.02 \mathrm{~m}^{3}$ & $2.5 \mathrm{~mm}$ & $10.0 \mathrm{~mm}$ & $37.1 \mathrm{~kg}$ \\
\hline LH2-OE & 2 & $0.25 \mathrm{~m}$ & $0.80 \mathrm{~m}$ & $0.019 \mathrm{~m}^{3}$ & $2.5 \mathrm{~mm}$ & $10.0 \mathrm{~mm}$ & $33.4 \mathrm{~kg}$ \\
\hline
\end{tabular}

Table 3. Main geometry and mass for the line-to-line model with branched crossfeed lines.

The total mass of the feedline system as calculated by PMP is $4602.8 \mathrm{~kg}$, which is approx. $600 \mathrm{~kg}$ less than for the previous approach. 


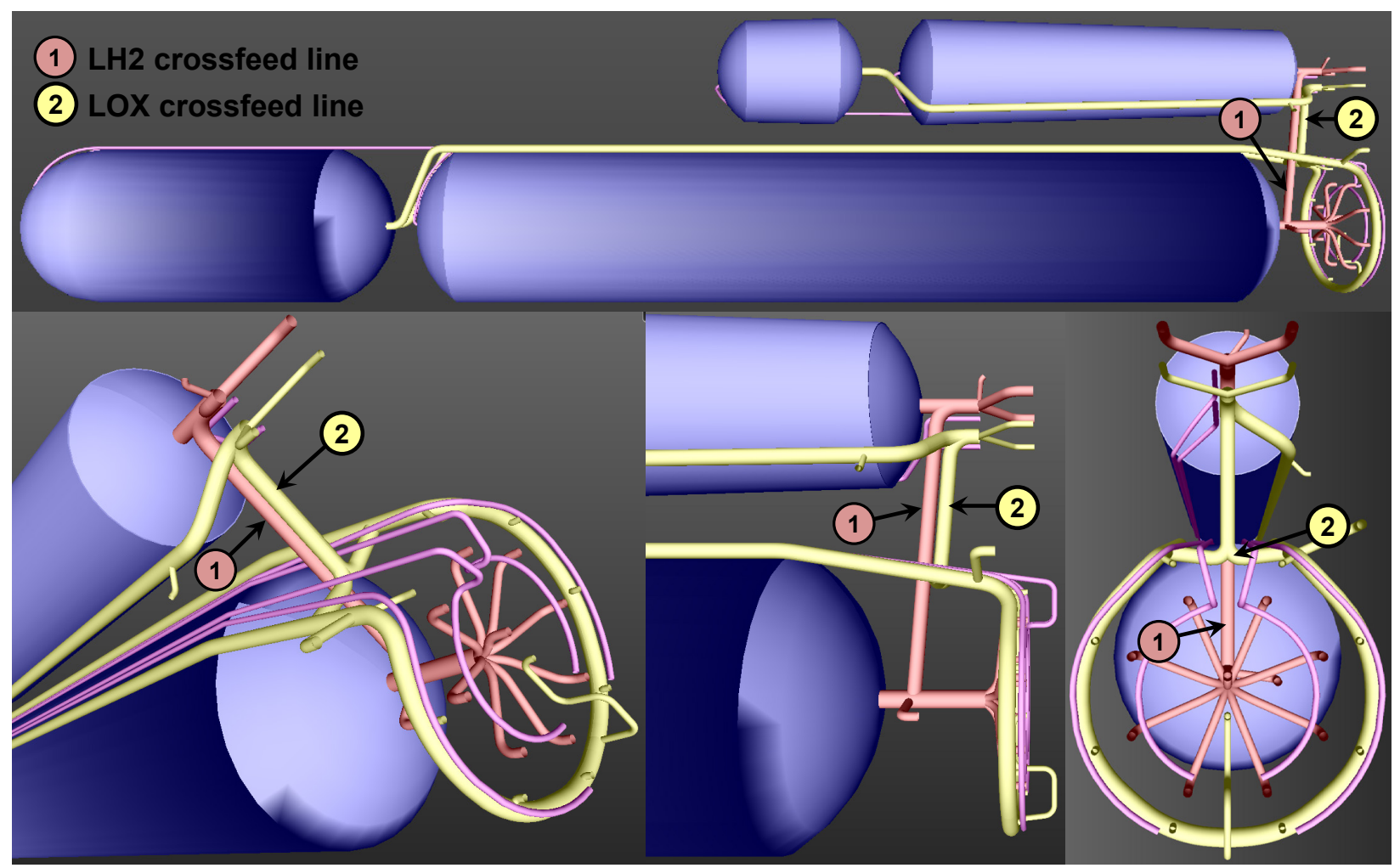

Figure 15. PMP line-to-line model for steady simulations, branching crossfeed pipes.

The configuration of the pressurization lines used in the preliminary analysis is also shown in Figure 15. There are two pressurization lines for each of the booster tanks and one for each of the orbiter tanks. An evaporation cycle is used, where propellant is recycled from the engine cycle back to the tanks to act as pressurization gas. Therefore, each LOX tank is pressurized with GOX and each LH2 tank with GH2.

Table 4 shows the tank pressure for each tank, as determined by the preliminary feedline analysis with and without consideration of venting. If venting is avoided, the ullage pressure might increase due to the incoming heat as long as no mass flow is extracted from the tank. The temperature for the pressurization gas was modeled after the Ariane 5 system $^{21}$. As pressurization gas temperature goes up, the amount that is required decreases, but achievable temperatures depend on the engine cycle and other parameters that are beyond the scope of this report. The pressure in the feedlines and the crossfeed lines are affected by the tank pressures and the gravity and acceleration of the vehicle. The internal pressure is a dimensioning parameter for the feedline system. Therefore the particular pressures at certain points are presented in the following as a function of the flight time.

\begin{tabular}{c|c|c|c|c|c}
\hline Tank & $\begin{array}{c}\text { Initial design } \\
\text { tank pressure }\end{array}$ & Press. gas & $\begin{array}{c}\text { Press. gas } \\
\text { temperature }\end{array}$ & $\begin{array}{c}\text { Total press. } \\
\text { gas mass }\end{array}$ & $\begin{array}{c}\text { Total mass } \\
\text { press. system }\end{array}$ \\
\hline \multicolumn{6}{c}{ Without Venting } \\
\hline LOX-B & $210 \mathrm{kPa}$ & GOX & $300 \mathrm{~K}$ & $2503 \mathrm{~kg}$ & $3045 \mathrm{~kg}$ \\
\hline LH2-B & $260 \mathrm{kPa}$ & GH2 & $120 \mathrm{~K}$ & $1298 \mathrm{~kg}$ & $1753 \mathrm{~kg}$ \\
\hline LOX-O & $460 \mathrm{kPa}$ & GOX & $300 \mathrm{~K}$ & 950 & $1108 \mathrm{~kg}$ \\
\hline LH2-O & $215 \mathrm{kPa}$ & GH2 & $120 \mathrm{~K}$ & 149 & $273 \mathrm{~kg}$ \\
\hline \multicolumn{7}{|c|}{ With Venting } \\
\hline LOX-B & $210 \mathrm{kPa}$ & GOX & $300 \mathrm{~K}$ & $2503 \mathrm{~kg}$ & $3045 \mathrm{~kg}$ \\
\hline LH2-B & $260 \mathrm{kPa}$ & GH2 & $120 \mathrm{~K}$ & $1298 \mathrm{~kg}$ & $1753 \mathrm{~kg}$ \\
\hline LOX-O & $460 \mathrm{kPa}$ & GOX & $300 \mathrm{~K}$ & $978 \mathrm{~kg}$ & $1136 \mathrm{~kg}$ \\
\hline LH2-O & $215 \mathrm{kPa}$ & GH2 & $120 \mathrm{~K}$ & $176 \mathrm{~kg}$ & $300 \mathrm{~kg}$ \\
\hline
\end{tabular}

Table 4. Mass data for the pressurization system. 
The pressure at certain points in the booster feedline system is shown in Figure 16. Compared to the previous approach, there is no rapid LOX pressure drop prior to the separation because there is no LOX stored in the additional feedline volume. Therefore the propellant in the tank is almost exactly consumed until the booster engine shut-off, but the feedlines are still completely filled, so that the hydraulic head is still relatively high. The NPSP at the turbopump entry is always above its minimum value, including large safety margins. Compared to the previous configuration the pressure level is generally higher due to the lower losses because of the increased line diameters. This can also be observed for LH2. The minimum NPSP is approx. $120 \mathrm{kPa}$, whereas it was $70 \mathrm{kPa}$ for the previous approach.

It must be noted that branching crossfeed lines still cause some inaccuracies and problems in PMP, because the code is not completely adapted to calculate such architectures yet. Therefore the pressure in the crossfeed line is not shown here. However, it might be assumed, that it is slightly lower than the pressure at the particular booster feedline branch.
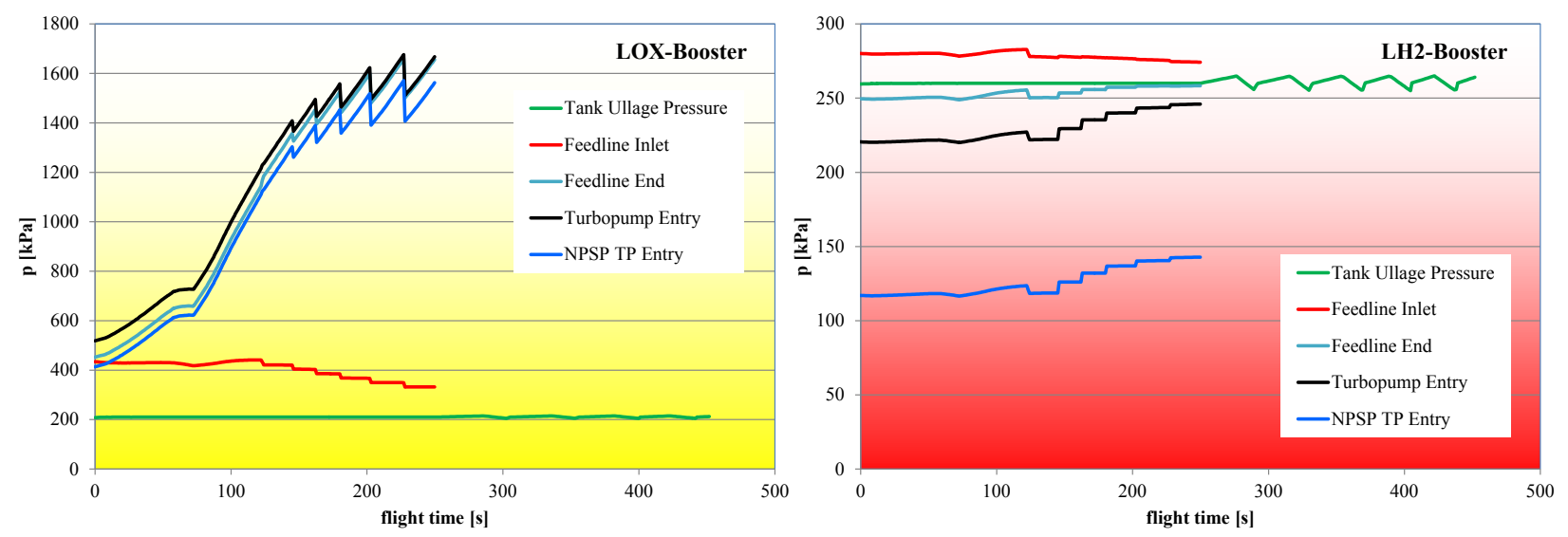

Figure 16. Pressure at certain points of the booster propellant system (branching crossfeed line).

Figure 17 shows the line pressure for the orbiter system. Because of the mentioned problems with branching crossfeed lines in PMP, only the tank ullage pressure and the pressure at the crossfeed line inlet branching are shown up to a flight time of approx. 250s. It must be assumed, that the pressure at the end of the crossfeed line is lower than at the inlet branching because of line and valve pressure losses. However, the crossline inlet pressure is still very high and therefore also the minimum NPSP at the orbiter turbopump entry is supposed to be high enough. Nevertheless these aspects have to be investigated in the future and an accordant update of PMP is already planned to be implemented. After booster separation, the pressure does not drop below the minimum NPSP for both oxygen and hydrogen.
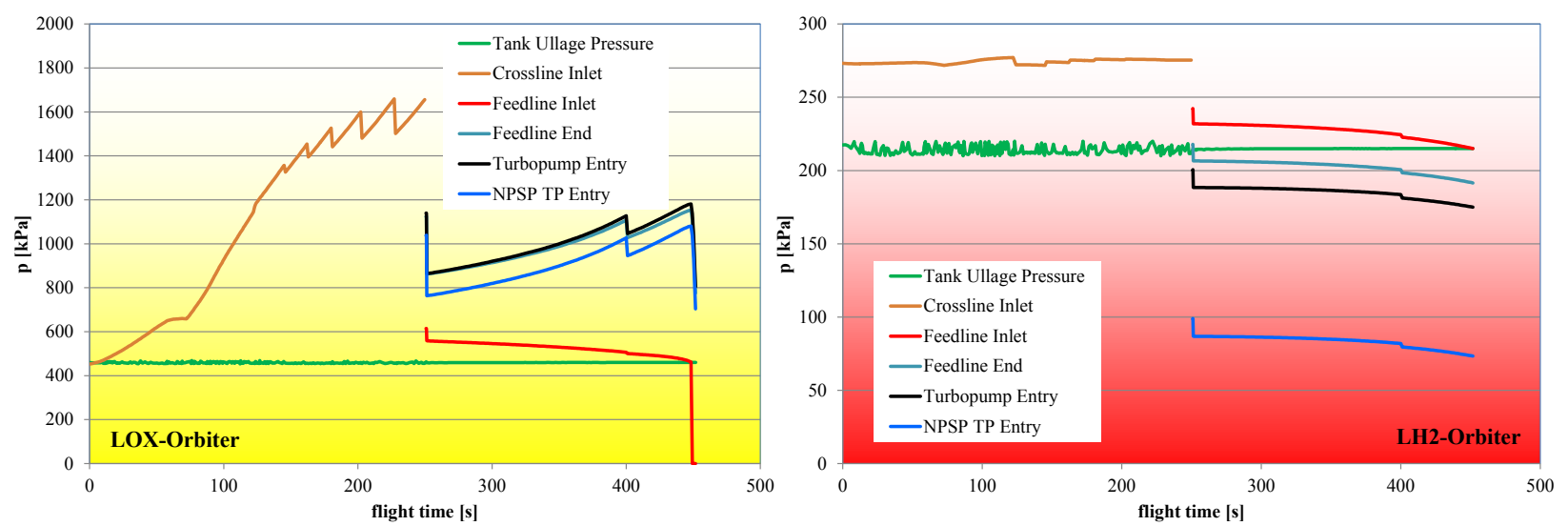

Figure 17. Pressure at certain points of the orbiter propellant system, including the pressure at the crossfeed branching inlet (branching crossfeed line). 


\section{B. Tank-to-Tank}

It must be noted that PMP was not implemented to simulate propellant crossfeed from tank to tank. However, it can be used to approximately calculate the most important parameters. The design and calculation method is exemplified in the following (Figure 18). The small diameter lines (pink) are pressurization lines. The LOX-tanks are pressurized by GOX and the LH2-tanks are pressurized by GH2 to avoid external helium pressurization and therefore additional system complexity. The crossfeed lines for both LOX and LH2 connect the booster and the orbiter tanks, whereas the orbiter engines are always fed from the orbiter feedlines as shown in Figure 18.

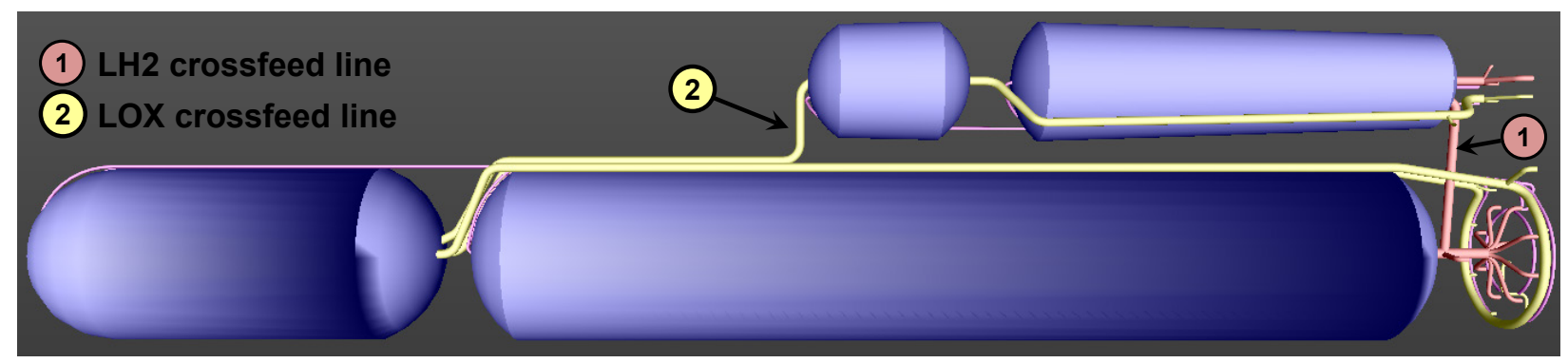

Figure 18. Tank-to-Tank crossfeed design generated with PMP.

For the booster propellant system, the pressures are almost similar to the first approach of the line-to-line configuration (Figure 19). The only differences are the adapted regulation of the tank ullage pressure due to increased venting valve diameters and the significantly lower crossfeed valve pressure for LOX. This is caused by the lower hydraulic head due to the forward location of the valve. The total vented gas mass is $375.16 \mathrm{~kg}$ of LOX and $257.32 \mathrm{~kg}$ of LH2.
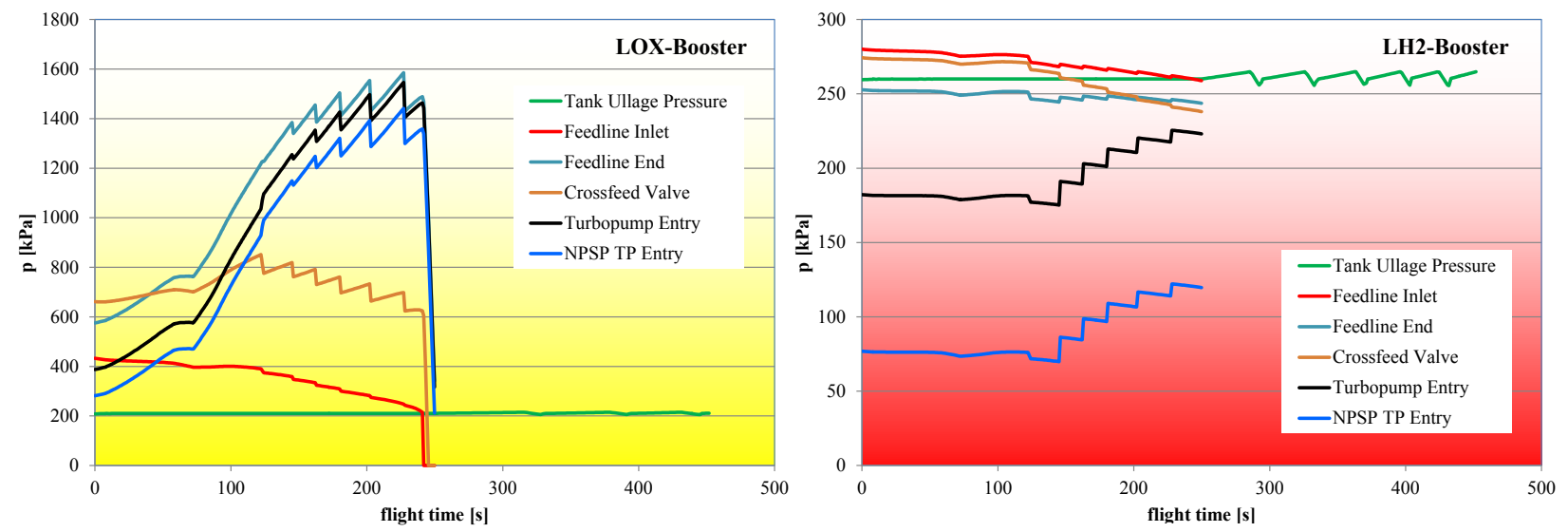

Figure 19. Pressure at certain points of the booster tank-to-tank propellant system, including the crossfeed line pressure.

As inflow into tanks cannot be directly modeled by PMP, two calculations must be conducted for the orbiter stage. In the first one, the orbiter pressure data were only calculated based upon the booster crossfeed data. In the second simulation the orbiter data were calculated only based upon the orbiter tank data without considering the crossfeed from the booster. The results for the LOX system are shown in Figure 20. The pressure values, calculated based on the crossfeed data are considerably higher than the pressure calculated only based on the orbiter tank data. This is caused by the difference in the hydraulic head between the booster and the orbiter LOX tanks, which influences the orbiter tank ullage pressure. Only short time before separation, the pressure rapidly decreases, which is due to the simplified modeling and not close to reality, as already explained. The particular data for the LH2 system are shown in Figure 21. The pressure differences between both calculations are smaller due to the lower density of LH2 and the lower hydraulic head. 

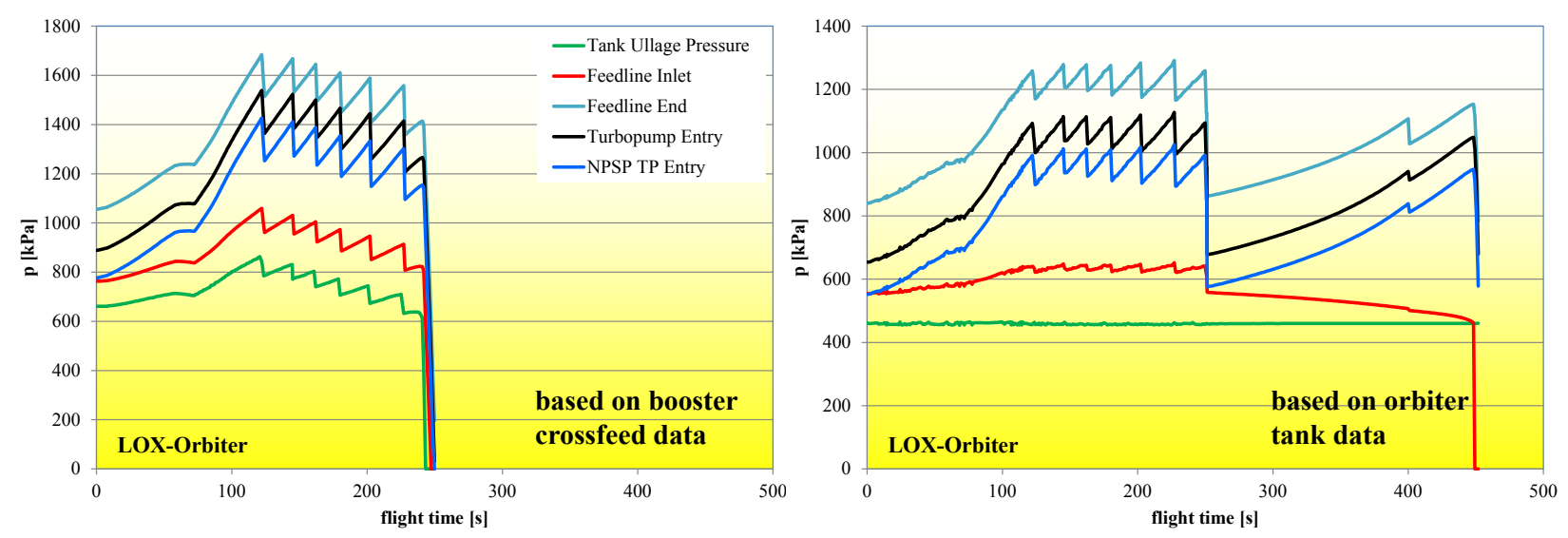

Figure 20. Pressure at certain points of the orbiter LOX system, (two different approaches).
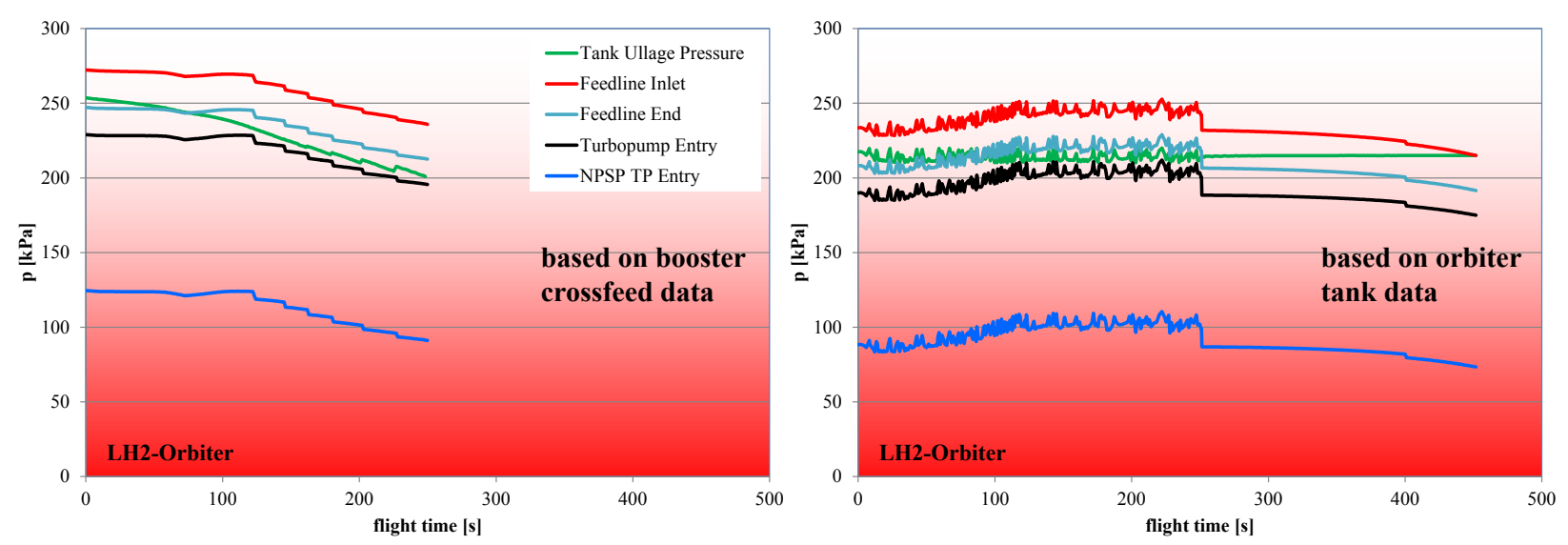

Figure 21. Pressure at certain points of the orbiter LH2 system (two different approaches).

However, the approach of the real pressure gradient for LOX and LH2, which is assumed in the following, is that both calculations are compared and the pressure is always the maximum of both. The results are given in Figure 22.
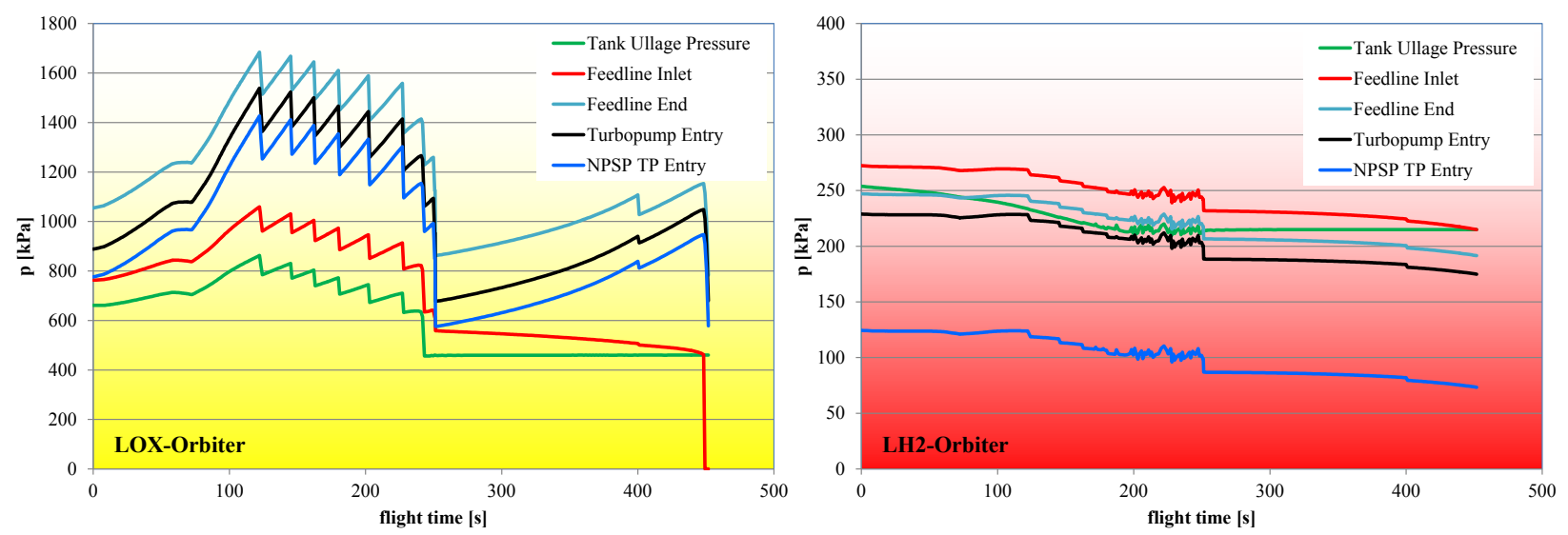

Figure 22. Pressure at certain points of the orbiter tank-to-tank propellant system.

For LH2 the pressure in the orbiter propellant system gets higher than in the booster-crossfeed system at a flight time of approx. 180s. This means that passive transport is not possible here. Therefore either the ullage pressure of the booster LH2-tank had to be increased or the fuel had to be actively transported by a pump. For LOX active transport would not be required.

Table 5 gives an overview of the feedline geometry and mass data for the first tank-to-tank architecture. It must be noted that, except for the crossfeed lines, all feedline data are fully similar to the data shown in Table 3 . Therefore 
only the crossfeed line data are given here. It is noticeable that the total length is calculated even longer than for the first line-to-line approach. This was found to be caused by internal line elements such a bellows, which were designed larger for the line-to-line system by PMP. Considering these circumstances, it becomes obvious, that PMP can only give a first estimation and further detailed design of the system will be necessary in the future.

\begin{tabular}{c|c|c|c|c|c|c|c}
\hline Line & $\begin{array}{c}\text { Number } \\
\text { of lines }\end{array}$ & $\begin{array}{c}\text { Internal } \\
\text { diameter }\end{array}$ & $\begin{array}{c}\text { Total } \\
\text { length }\end{array}$ & $\begin{array}{c}\text { Internal } \\
\text { volume }\end{array}$ & $\begin{array}{c}\text { Struct. } \\
\text { thickness }\end{array}$ & $\begin{array}{c}\text { Insolation } \\
\text { thickness }\end{array}$ & $\begin{array}{c}\text { Total } \\
\text { mass }\end{array}$ \\
\hline LOX-C & 1 & $0.4 \mathrm{~m}$ & $24.31 \mathrm{~m}$ & $2.626 \mathrm{~m}^{3}$ & $2.5 \mathrm{~mm}$ & $10.0 \mathrm{~mm}$ & $378.5 \mathrm{~kg}$ \\
\hline LH2-C & 1 & $0.4 \mathrm{~m}$ & $10.28 \mathrm{~m}$ & $1.19 \mathrm{~m}^{3}$ & $2.5 \mathrm{~mm}$ & $100.0 \mathrm{~mm}$ & $398.3 \mathrm{~kg}$ \\
\hline
\end{tabular}

Table 5. Main crossfeed line geometry and mass.

The venting valves were slightly adapted to the new conditions, but, using simplified assumptions, pressurizing and venting of the orbiter tank cannot be properly considered by PMP from lift-off until booster separation, because in reality the orbiter tank is connected to the booster tank via the crossfeed line. Table 6 shows the Tank pressure for each tank, as determined by the preliminary feedline analysis.

\begin{tabular}{c|c|c|c|c|c}
\hline Tank & $\begin{array}{c}\text { Initial design } \\
\text { tank pressure }\end{array}$ & Press. gas & $\begin{array}{c}\text { Press. gas } \\
\text { temperature }\end{array}$ & $\begin{array}{c}\text { Total press. } \\
\text { gas mass }\end{array}$ & $\begin{array}{c}\text { Total mass } \\
\text { press. system }\end{array}$ \\
\hline LOX-B & $210 \mathrm{kPa}$ & $\mathrm{O} 2$ & $300 \mathrm{~K}$ & $2457 \mathrm{~kg}$ & $3106 \mathrm{~kg}$ \\
\hline LH2-B & $260 \mathrm{kPa}$ & $\mathrm{H} 2$ & $120 \mathrm{~K}$ & $1304 \mathrm{~kg}$ & $1759 \mathrm{~kg}$ \\
\hline LOX-O & $460 \mathrm{kPa}$ & $\mathrm{O} 2$ & $300 \mathrm{~K}$ & $890 \mathrm{~kg}$ & $1048 \mathrm{~kg}$ \\
\hline LH2-O & $215 \mathrm{kPa}$ & $\mathrm{H} 2$ & $120 \mathrm{~K}$ & $145 \mathrm{~kg}$ & $269 \mathrm{~kg}$ \\
\hline
\end{tabular}

Table 6. Mass data for the pressurization system (with venting).

\section{Transient Simulations}

Within this section, the dynamic behavior of the fluid in the system shall be investigated to identify potential issues related to the transient phases such as booster separation. EcosimPro is utilized for the modeling. The components used in EcosimPro require a lot of input data, which is not always known in advance. Therefore different approaches are made during the simulations. The sensitivity for errors or non-convergence normally increases with the complexity of the model as well as the computation time increases. Therefore it is always tried to keep the models rather simple to get the basic information about the system and the parameters. Separated analyses are conducted for the LOX and the LH2 system as well as for the different design architectures. Based on the statements in the literature references it can be assumed, that the line-to-line model design is the simplest of the three architectures, thus the first studies concentrate on this system for both, LOX and LH2. The results of the steady simulations can be taken as a baseline for the transient analyses. Therefore it must be noted that, due to the totally different methods which are implemented in the tools, the required input data of PMP and EcosimPro are not always the same and thus, the results might be different to some extent.

Within the CHATT project, lots of simulations and models were investigated. The most important results are summarized below. The detailed studies and extensive results can be found in Ref. 22.

\section{A. Line-to-Line}

The approach for modeling of the line-to-line architecture is shown in Figure 23 exemplary for LH2. This model is suitable to simulate only the moment of separation and conduct parametric studies with respect to the mass flow and pressure fluctuations, which might occur at the orbiter engines during separation. The valve opening and closing is realized via time dependent opening and closing valves. In this modeling approach the mass flow at the turbopump entry is a function of the other system parameters such as line cross section areas and pressures. Therefore backflow through the feedlines would also be possible in this approach. Therefore the system is adapted to almost fit the conditions which were determined during the steady analyses. In the real propellant system, the mass flow is rather determined by the turbopump characteristics and not only by the pressure in the lines. But, to run the turbopumps at safe conditions and prevent cavitation, strong oscillation of the pressure should be avoided and the inlet pressure must be large enough to achieve the minimum required NPSP.

For the liquid hydrogen the average temperature of $20 \mathrm{~K}$, the saturation pressure is $\mathrm{p}_{\mathrm{sat}}=93.414 \mathrm{kP}$. Assuming a minimum required NPSP of $70 \mathrm{kPa}$ the pressure at the turbopump entry should not fall below $\mathrm{p}_{\min }=163.414 \mathrm{kPa}$. 

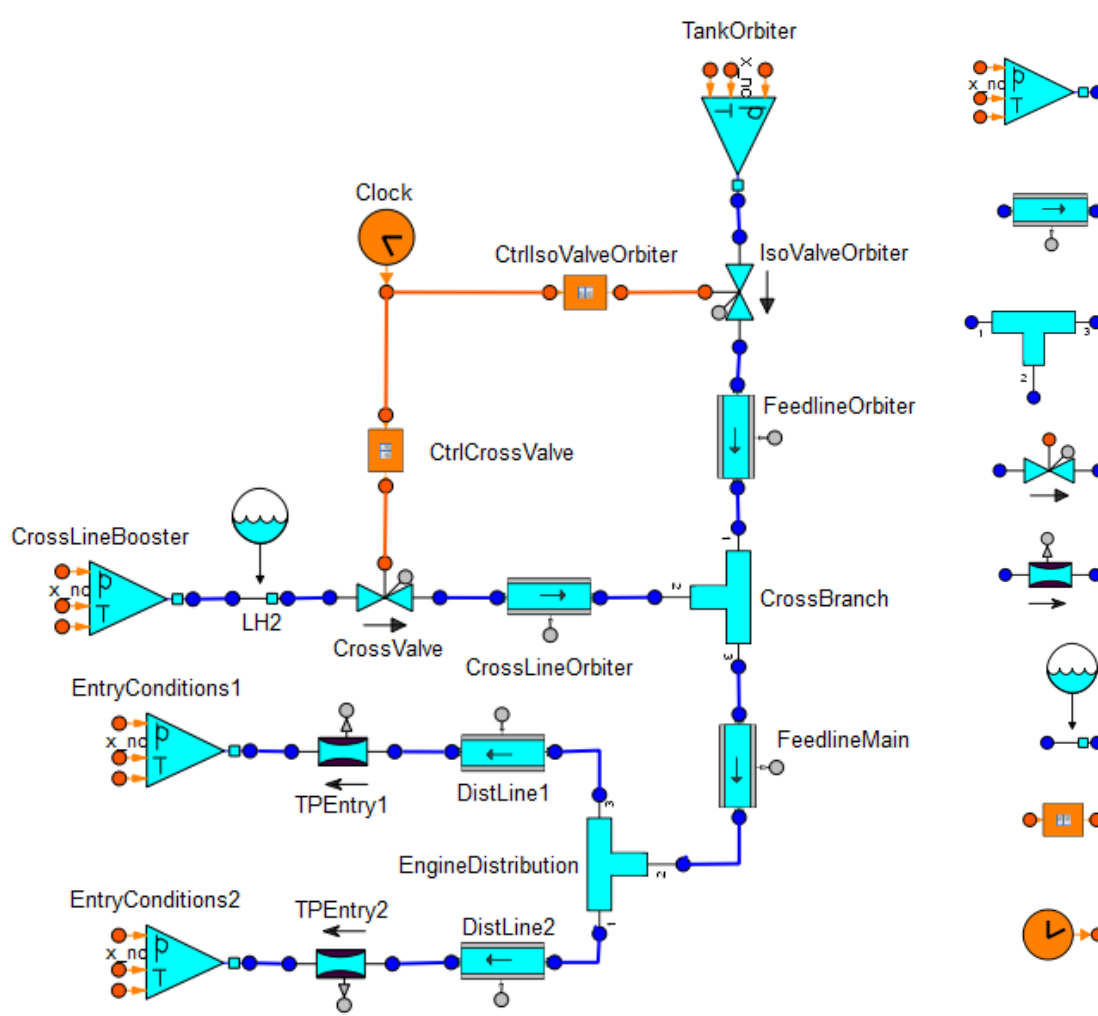

Time dependent boundary condition

in P-T (signal inputs)

Cylindrical area-varying non-uniform

$\rightarrow$ mesh high resolved 1D pipe with one wall thermal node per fluid node

$\square-\square$ Adiabatic Tee to simulate a joint or $=$ a split of two branches

Figure 23. EcosimPro line-to-line modeling approach for LH2.

The saturation pressure of LOX at the average temperature of $90 \mathrm{~K}$ is $99.35 \mathrm{kPa}$. Assuming the minimum defined NPSP of $230 \mathrm{kPa}$ the minimum allowed pressure at the turbopump entry would be approx. $330 \mathrm{kPa}$.

As the opening and closing time of the valves is the main impact factor on the water hammer effect, a test matrix is built up to consider the influence of valve timing during the simulations (Table 7). $t_{\text {start }}$ is the time, when the crossfeed mass flow control valve starts to close or the orbiter mass flow control valve starts to open. The valve closure and opening characteristics are assumed to be a linear function of the closing time $t_{\text {close }}$ or the opening time $t_{\text {open }}$ until the valve is fully closed or open $\left(t_{\text {end }}=t_{\text {start }}+t_{\text {open/close }}\right)$. All times are referred to $t_{0}$, which is the time, when the crossfeed mass flow control valve starts to close.

\section{Hydrogen}

The turbopump entry is the most critical region in terms of pressure and mass flow oscillations and therefore the results of the simulation are given for this point. The mass flow data at the turbopump entry is

\begin{tabular}{c|cc|cc}
\hline \multirow{2}{*}{ No. } & \multicolumn{2}{|c|}{ CrossValve } & \multicolumn{2}{c}{ IsoValveOrbiter } \\
& $\mathbf{t}_{\text {start }}$ & $\mathbf{t}_{\text {close }}$ & $\mathbf{t}_{\text {start }}$ & $\mathbf{t}_{\text {open }}$ \\
\hline 1 & $\mathrm{t}_{0}$ & $0.5 \mathrm{~s}$ & $\mathrm{t}_{0}$ & $0.5 \mathrm{~s}$ \\
\hline 2 & $\mathrm{t}_{0}$ & $1.0 \mathrm{~s}$ & $\mathrm{t}_{0}$ & $1.0 \mathrm{~s}$ \\
\hline 3 & $\mathrm{t}_{0}$ & $2.0 \mathrm{~s}$ & $\mathrm{t}_{0}$ & $2.0 \mathrm{~s}$ \\
\hline 4 & $\mathrm{t}_{0}$ & $0.5 \mathrm{~s}$ & $\mathrm{t}_{0}+1 \mathrm{~s}$ & $0.5 \mathrm{~s}$ \\
\hline 5 & $\mathrm{t}_{0}$ & $1.0 \mathrm{~s}$ & $\mathrm{t}_{0}+1 \mathrm{~s}$ & $1.0 \mathrm{~s}$ \\
\hline 6 & $\mathrm{t}_{0}$ & $2.0 \mathrm{~s}$ & $\mathrm{t}_{0}+1 \mathrm{~s}$ & $2.0 \mathrm{~s}$ \\
\hline 7 & $\mathrm{t}_{0}$ & $0.5 \mathrm{~s}$ & $\mathrm{t}_{0}-1 \mathrm{~s}$ & $0.5 \mathrm{~s}$ \\
\hline 8 & $\mathrm{t}_{0}$ & $1.0 \mathrm{~s}$ & $\mathrm{t}_{0}-1 \mathrm{~s}$ & $1.0 \mathrm{~s}$ \\
\hline 9 & $\mathrm{t}_{0}$ & $2.0 \mathrm{~s}$ & $\mathrm{t}_{0}-1 \mathrm{~s}$ & $2.0 \mathrm{~s}$ \\
\hline
\end{tabular}

Table 7. Valve closing time test matrix for the simulations. qualitatively the same than for the main feedline but exactly half the value due to the symmetric splitting of the mass flow in the "EngineDistribution" branch (Figure 23). The mass flow during the separation is shown in Figure 24 as a function of the time. According to Figure 24 it can be noted that the mass flow peaks during separation get less critical and the mass flow drop is more continuous with increasing closing and opening time. The most beneficial results are achieved for test cases No.3 and No.9 whereas the worst cases are No.4 and No.5, where the mass flow drops down to zero. In these cases a catastrophic failure of the turbopumps seems very likely.

Figure 25 shows the pressure at the turbopump entries as a function of the time. Principally the same observations than for the mass flow can be made. The peaks and oscillations in pressure get more critical for short valve opening and closing times, especially for test No.4. As it was previously shown for the mass flows, the orbiter isolation valve opens $0.5 \mathrm{~s}$ after the crossfeed valve is fully closed. At this time, there is almost no mass flow in the lines anymore. Therefore the sudden opening of the orbiter isolation valve causes a strong water hammer effect. 
Even if the pressure never falls below its minimum required value at the turbopump entry, it is very likely that the strong oscillations might cause severe problems to the turbopumps. As for the mass flow, the tests No.2, No.3, No.8 and No.9 show the most beneficial pressure gradient.
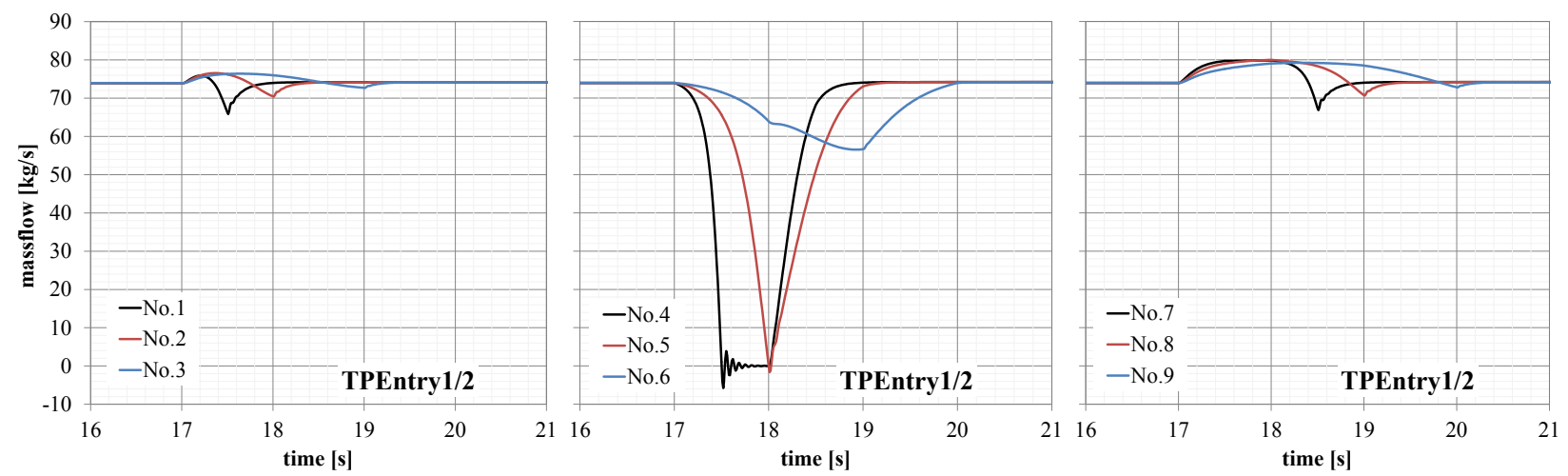

Figure 24. LH2 mass flow data at the orbiter turbopump entries during separation for line-to-line approach.
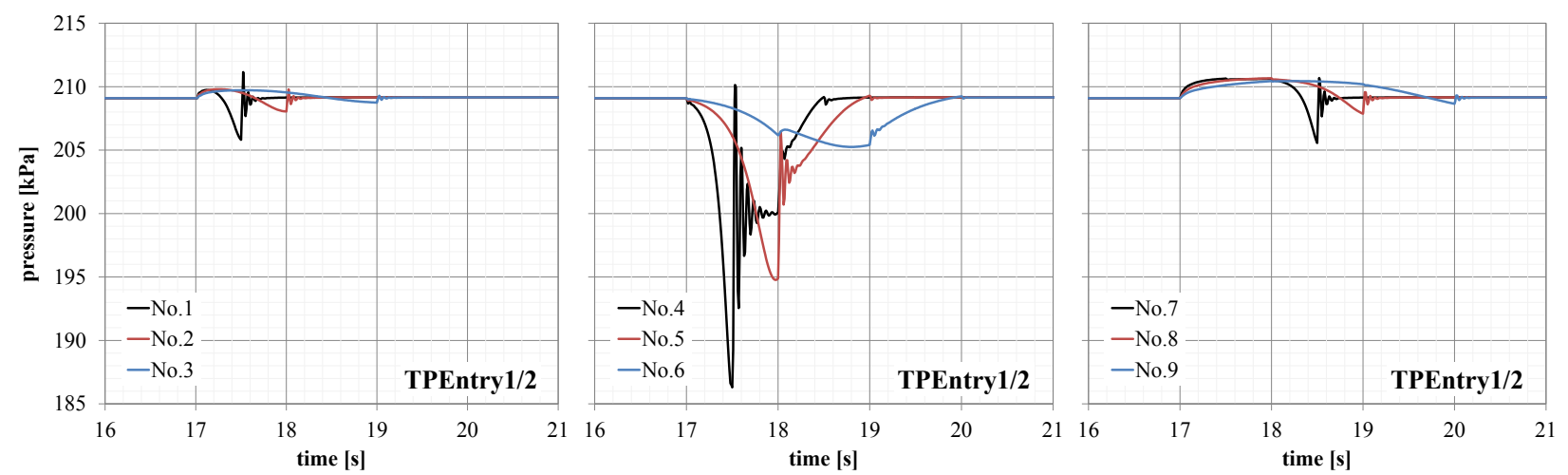

Figure 25. LH2 pressure data at the orbiter turbopump entries during separation for line-to-line approach.

\section{Oxygen}

The same model which is shown in Figure 23 for LH2 is also applied for the LOX simulations. The respective results in terms of mass and pressure gradients are shown in Figure 26 and Figure 27. As for LH2 the transients get more severe for short closing times, and in particular in case of delayed opening of the orbiter feedline valve. However, due to the higher density of LOX, the amplitudes of the oscillation are much larger than for LH2. In general it can be stated that mass increases are less critical than mass decreases, because in the reality the mass flow would be defined by the turbopump power anyway but therefore a mass increase in this simulation would either result in a pressure increase or might be throttled whereas a mass decrease would result in a pressure decrease and cannot be throttled. Therefore the simultaneous opening/closing of the valves and the delayed closure of the crossfeed valve are the more attractive timing options.
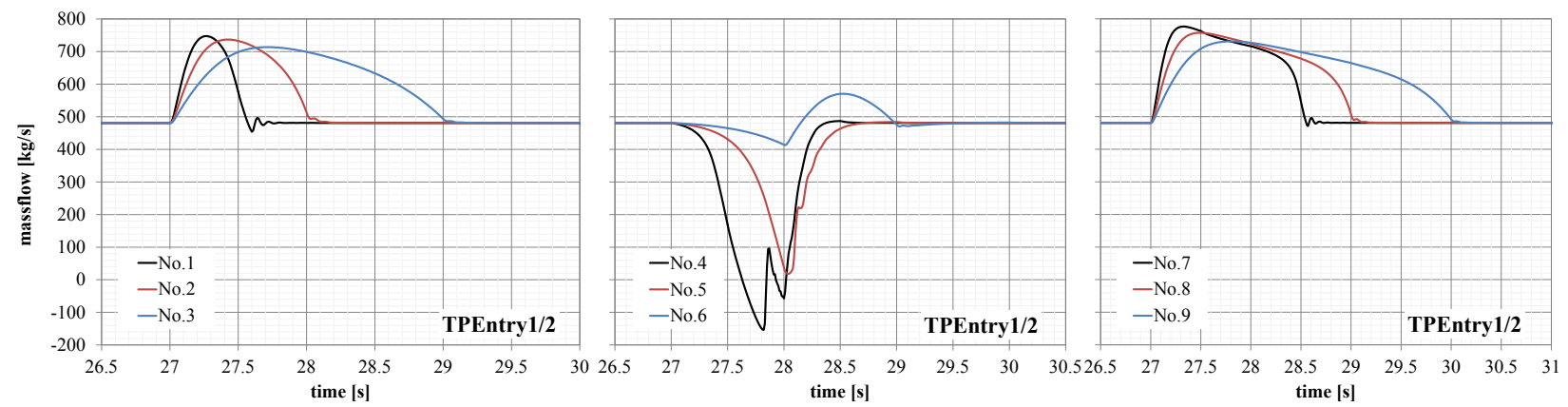

Figure 26. LOX mass flow data at the orbiter turbopump entries during separation for line-to-line approach.

American Institute of Aeronautics and Astronautics 

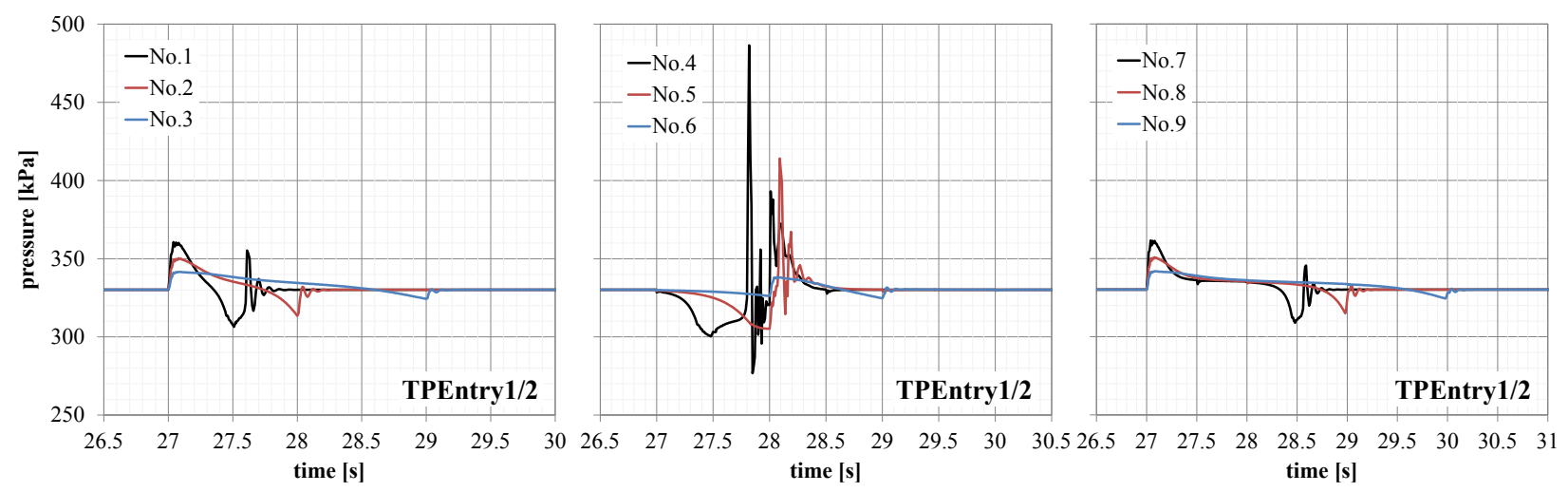

Figure 27. LOX pressure data at the orbiter turbopump entries during separation for line-to-line approach.

As a general conclusion of the line-to-line simulations it can be stated that longer valve opening and closing times should be preferred, because in all simulations it was found, that the most critical transients occur for very short separation times. Furthermore the simultaneous opening and closing of both valves seems to be the most attractive solution. Untimely closing of the crossfeed valve causes the most severe transients, whereas a delayed closing of the crossfeed valve was found to be less critical. However, small pressure drops can even occur in the most beneficial cases. These aspects should be considered for the design of the system.

\section{B. Tank-to-Tank}

Within this section, the model for the transient simulations of the tank-to-tank architecture is introduced. The model is adapted for both liquid hydrogen and oxygen. Similar to the line-to-line simulations the main focus is on the timing of valve opening and closing, which, according to the literature data, is a dimensioning parameter. Furthermore the internal ullage pressure in the orbiter tank during the separation is important for the structural tank design. The modeling approach for the tank-to-tank simulations in EcosimPro is shown in Figure 28.

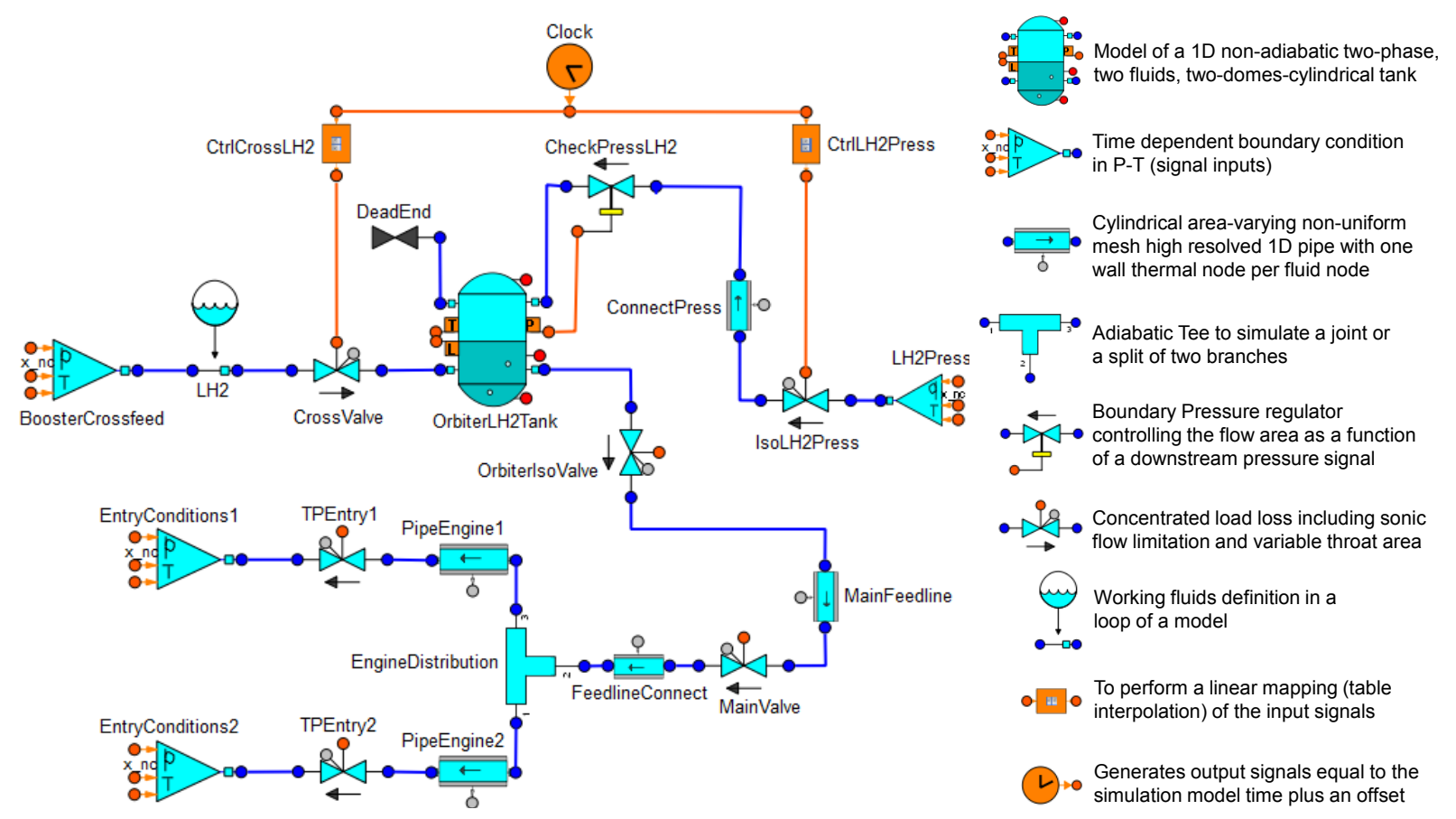

Figure 28. EcosimPro tank-to-tank modeling approach for LH2.

Some geometry dimensions of the pipe system components are principally very similar to the line-to-line approach whereas the pressures slightly deviate, due to the different design architecture. In particular the pressure in the crossfeed line must be high enough to overcome the hydrostatic pressure in the tank because the connection is 
foreseen to be at the tank bottom. At booster separation, the crossfeed valve is closed and the pressurization gas valve for the orbiter tank is opened.

\section{Hydrogen}

The influence of the valve timing on the GH2 pressurization gas mass flow is shown in Figure 29 using the test matrix which was given in Table 7. In case of delayed opening (No.4 to No.6), a very high mass flow is going into the LH2 tank just in the moment of pressure valve opening. The relatively low tank pressure at that moment causes the valve to fully open, which, in conjunction with the relatively large pressure difference between pressurization gas source and tank, results in a gas mass flow peak. When the tank ullage pressure is then back at its design level, an almost constant gas mass flow is provided by the system to compensate the outgoing propellant volume. In case of simultaneous valve opening/closing or delayed crossfeed valve closing, there is no peak in pressure gas mass.
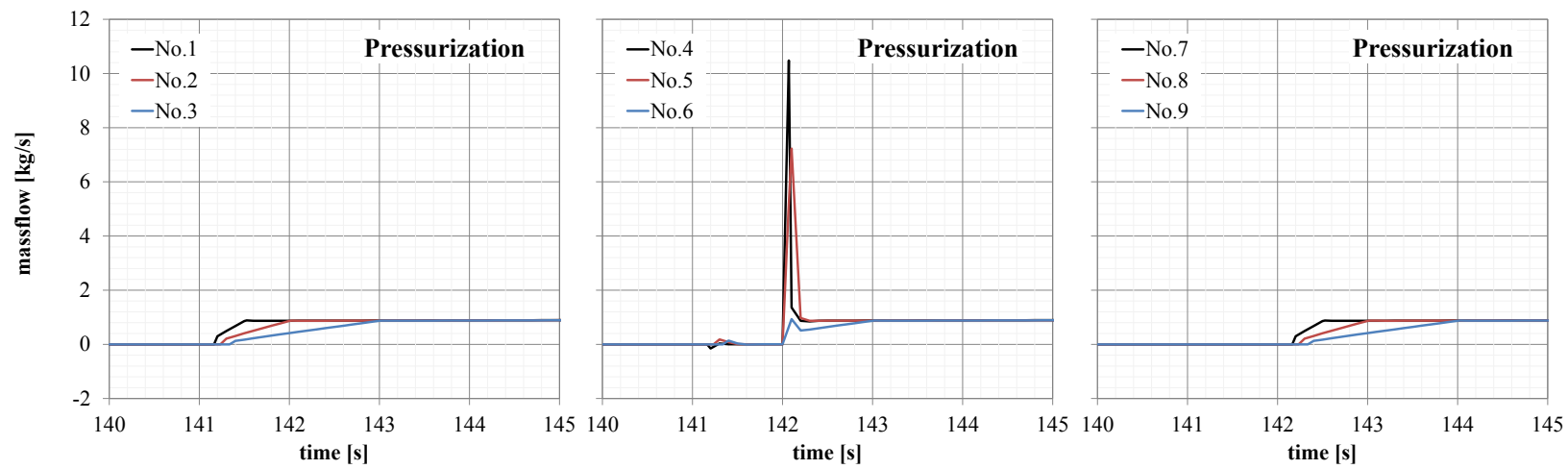

Figure 29. GH2 pressurization gas mass flow into the LH2 tank during separation for tank-to-tank approach.

Figure 30 shows the LH2 mass flow at the turbopump entry during the separation. It is obvious that the mass flow is directly dependent on the pressure at the LH2 tank bottom. Therefore a slight decrease of mass flow after separation can be observed, which is caused by the decreasing filling level and therewith by the decreasing hydrostatic pressure. For the delayed pressure valve opening a rapid decrease of mass flow happens during the separation. After opening of the pressure valve, the pressure rapidly increases to the design value. However, compared to the line-to-line approach this decrease and the transients during separation are still very small.
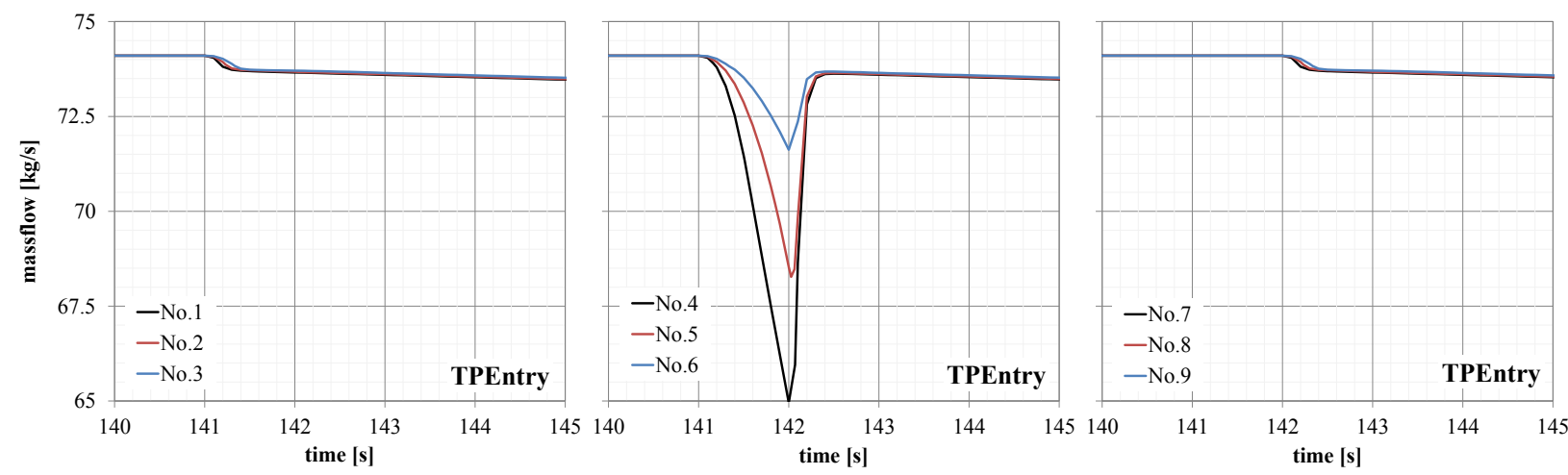

Figure 30. LH2 mass flow data at the orbiter turbopump entries during separation for tank-to-tank approach.

The LH2 tank ullage pressure during separation is shown in Figure 31. It is obvious that there are much less transients than for the line-to-line architecture, too, analog to the mass flow. This observation corresponds to the previously predicted system behavior. Before separation the tank ullage pressure is kept almost constant due to the incoming mass flow from the booster tank. After separation the pressure is kept constant by the orbiter tank pressurization system. Only in case of delayed pressurization valve opening, the pressure decreases, because there is neither an incoming mass flow nor the pressurization gas, which can counteract the pressure loss caused by the effusing propellant volume. However, there are no oscillations as for line-to-line and the maximum pressure loss is only approx. $25 \mathrm{kPa}$ for the worst case in simulation No.4. 

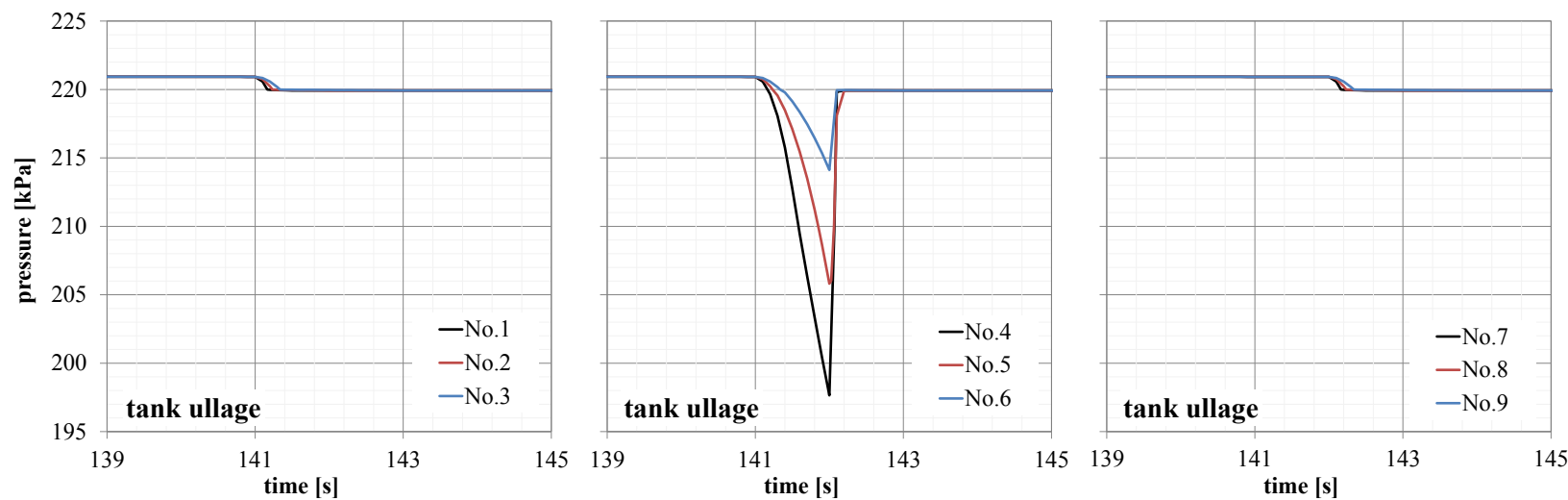

Figure 31. LH2 tank ullage pressure data during separation for tank-to-tank approach.

Figure 32 shows the pressure at the orbiter turbopump entries. Qualitatively, it is similar to the tank ullage pressure. The absolute values are, of course, different due to the hydraulic head differences and the pressure losses in the lines and branches. It can be noted that, even in the worst case (No.4) the pressure is still approx. 50kPa above the lower limit of $165 \mathrm{kPa}$.
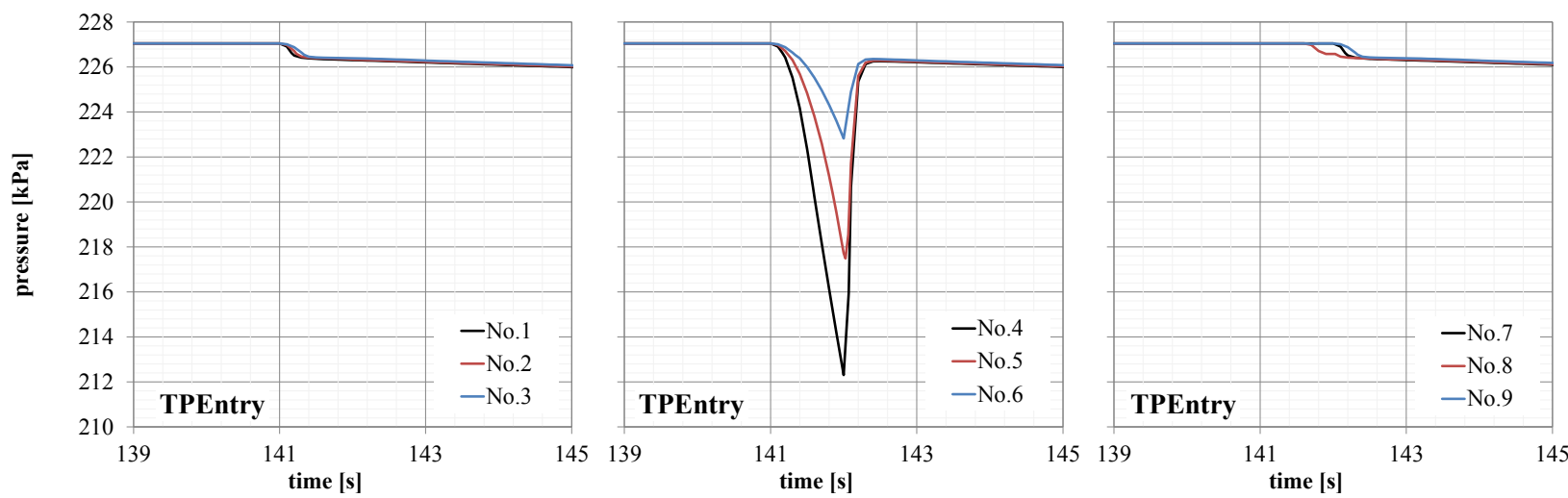

Figure 32. LH2 pressure data at the orbiter turbopump entries during separation for tank-to-tank approach.

\section{Oxygen}

The modeling approach for the LOX tank-to-tank simulation is quite similar to the LH2 approach (Figure 28). Of course, the parameters of the particular components are adapted to the LOX system. The GOX pressure gas mass flow after the opening of the pressurization isolation valve is shown in Figure 33.
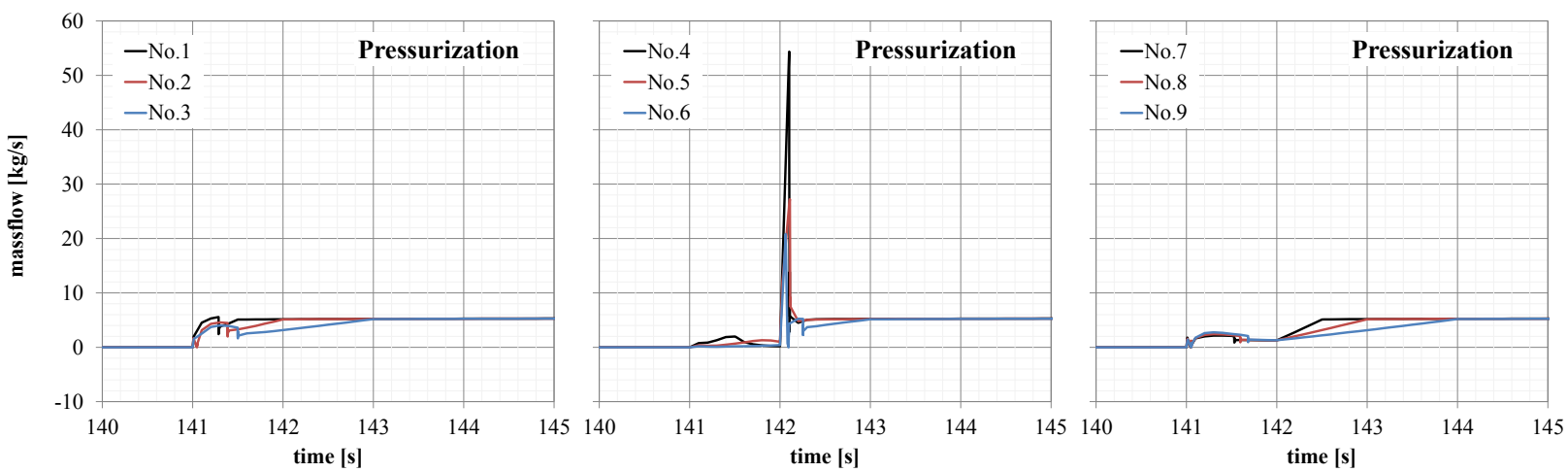

Figure 33. GOX pressurization gas mass flow into the LOX tank during separation for tank-to-tank approach. 
As for LH2 there are only very slight transients during the separation, except for the delayed pressure valve opening. This is for the same reason than already explained for LH2, however due to the higher density of LOX and the higher pressure drop, the peak mass flow is much higher here. After the separation the pressure gas mass flow is almost constant at approx. $6 \mathrm{~kg} / \mathrm{s}$. The mass flow at the turbopump entry is shown in Figure 34 . As for LH2, mass flow drops can only be observed for test No.4 to No.6, which are, percentaged, in the same order of magnitude than for $\mathrm{LH} 2$.
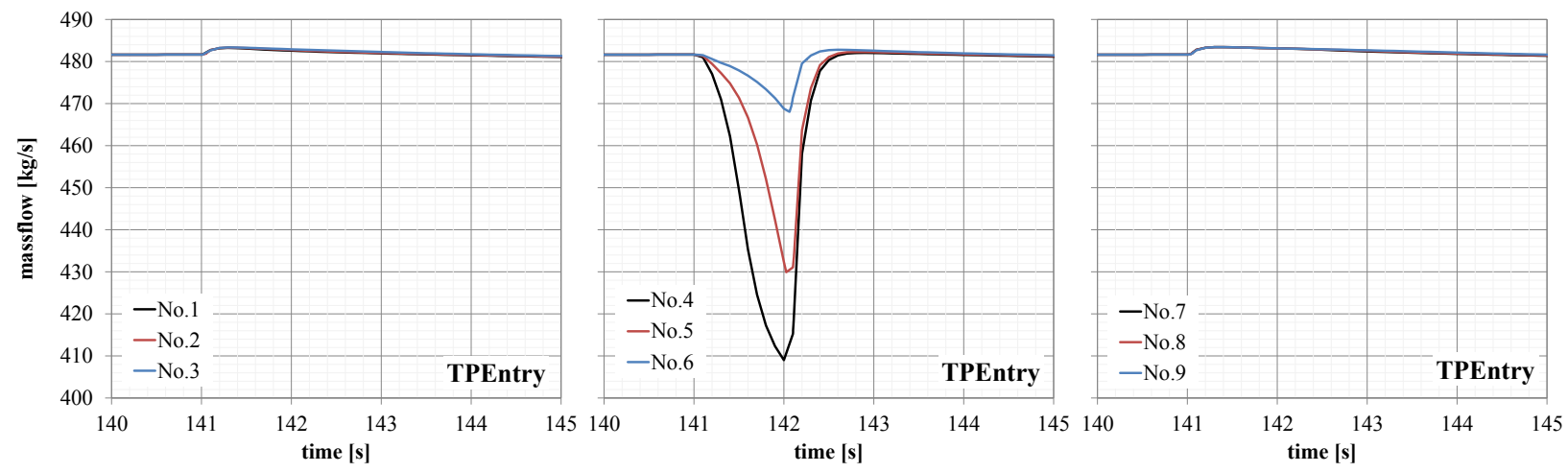

Figure 34. LOX mass flow data at the orbiter turbopump entries during separation for tank-to-tank approach.

The influence of the valve timing on the pressure in the tank ullage and at the turbopump entries is shown in Figure 35 and Figure 36. Same as for LH2 there are no transient pressure oscillations. Before separation the pressure is kept almost constant by the incoming crossfeed propellant volume flow. For synchronous valve timing and delayed crossfeed valve closing (No.1-No.3 and No.7-No.9) the pressure slightly increases during the separation. However, if necessary this increase could be avoided by regulating the pressurization more accurately. In cased of delayed pressure gas valve opening (No.4-No.6), there is also no oscillation but a large pressure drop. The absolute value of the pressure drop during the separation is almost similar at all system points and mainly caused by the drop in the ullage pressure. Compared to LH2 the pressure drop seems to be very high. This is because the initial filling level of the LH2 tank was only $96 \%$ of the volume, whereas the filling level of the LOX tank is $99.9 \%$, which results in a much smaller gas volume. When crossfeed is stopped, the gas volume in the tank rapidly increases by a multiple due to the effusing propellant flow while there is still no pressurization. Given these circumstances, as for all simulations, the case of preterm crossfeed valve closing is the most critical of all investigated timing cases. However, increasing the initial tank ullage volume could reduce the pressure drop during the separation.
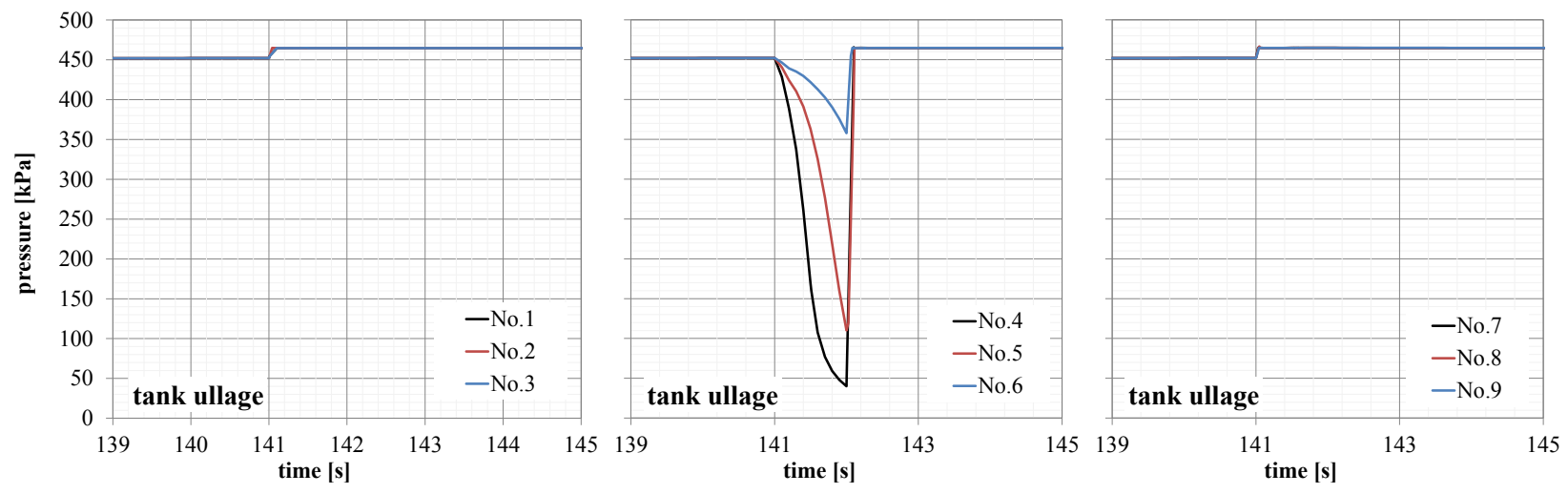

Figure 35. LOX tank ullage pressure data during separation for tank-to-tank approach.

After the separation the ullage pressure is kept on its design value by the pressurization system. The pressure in the remaining points of the system depends also on the hydrostatic pressure of the LOX and therefore decreases slowly with the tank filling level. Due to the high elevation of the tank, the pressure at the end of the main feedline and at the turbopump entry is much higher than at the tank bottom or in the ullage. 

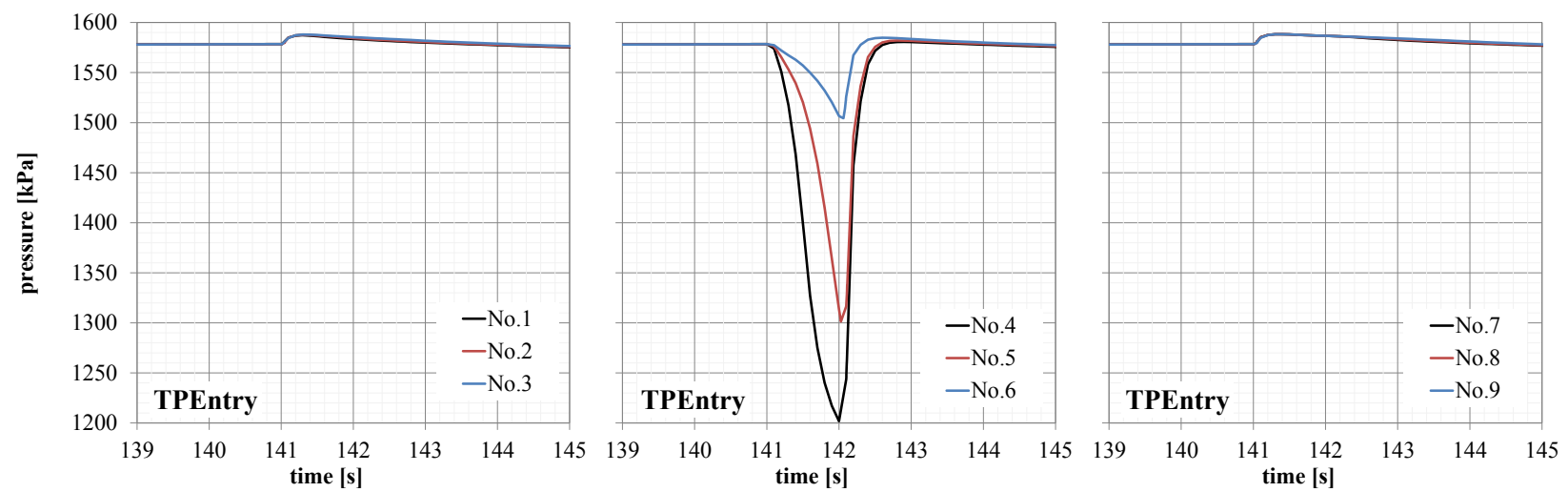

Figure 36. LOX pressure data at the orbiter turbopump entries during separation for tank-to-tank approach.

Compared to the line-to-line approach it is obvious, that the tank-to-tank architecture causes much less oscillations and transient issues. Unfavorable conditions might also occur in case of preterm crossfeed valve closing, which is less beneficial of all timing scenarios. The drops in pressure and mass flow can be reduced by increasing the ullage volume. However this means additional structural mass.

\section{Conclusion}

A preliminary design of the SpaceLiner tank and feedline system has been performed and analyzed for steady state and during transient phases.

In the steady analyses two architectures were pre-designed, line-to-line and tank-to-tank. Line-to-line is theoretically the simplest because it only requires the addition of a valve to switch feedlines for the orbiter engines during separation. However, it is extremely important that there is no oscillation in flow properties during this transition, which may be difficult to obtain given the extreme properties of the flow, in particular for the LOXsystem, where large pressure differences might occur at separation. These differences for LOX are less critical for the tank-to-tank approach due to the smaller difference in the hydraulic head. Tank-to-tank is more complicated, because it requires having flow into a tank, as well as out of it. Dependent on the tank position and filling level there might be the need for a pump system to move propellant from one tank to another. For the SpaceLiner configuration this might be the case for the LH2-system. For LOX another issue arises: Due to the relatively high hydraulic head between booster and orbiter LOX tank, high internal pressures can occur in the orbiter LOX tank, which results in high structural masses. Nevertheless, based on the steady simulations, the most promising option seems to have tank-to-tank crossfeed for the LOX system and line-to-line crossfeed for the LH2 system.

Based on the relatively simple transient models in EcosimPro it can be stated that the tank-to-tank architecture is the most beneficial approach to avoid transient pressure and mass flow issues. The tank-to-tank results show almost no oscillations and very low sensitivity to valve opening/closing times. Therefore this architecture would have the highest amount of reliability, even if there are valve control failures.

A general observation for all architectures was that the most critical case for the system is the delayed opening of the orbiter isolation valve, because in this case the mass flow is interrupted. In particular for the line-to-line architecture this would result in catastrophic failure of the turbopumps.

For the LOX system, the tank-to-tank approach is definitely recommended, because the transport can be conducted by the hydraulic head and there are almost no transient issues. Furthermore, the very high hydrostatic pressures, which might result in high ullage pressures in the orbiter tank, can be reduced by the implementation of a throttling valve. This will be investigated in further studies.

For LH2 the tank-to-tank design might be also an option. Slightly increasing the internal LH2 booster tank pressure can help to transport the LH2 into the orbiter tank, because the hydrostatic pressure of the LH2 is relatively low. This would definitely be better than adding an additional pump, which might cause system complexity and sensitivity for failure. If line-to-line should be used for LH2, the particular focus has to be on the valve timing and control.

The next steps of the propellant system studies will therefore be to investigate the full system along the full flight time, considering the statements made in this conclusion. Therefore more complex models in EcosimPro must be created to simulate the controlling of the pressure and mass flow along the full trajectory. Another interesting point would be how to manage the fuel transport in case of flight abort scenarios such as an engine failure. These open questions should be addressed in the future. 


\section{Acknowledgments}

This work was performed within the 'Cryogenic Hypersonic Advanced Tank Technologies' project investigating tank technologies for high-speed transport. CHATT, coordinated by DLR-SART, is supported by the EU within the 7th Framework Programme Theme 7 Transport, Contract no.: ACP1-GA-2011-285117. Further information on CHATT can be found on http://www.chatt.aero.

The authors gratefully acknowledge the contributions of Ms. Carola Bauer, Ms. Mona Carlsen, Mr. David Gerson, Mr. Ryoma Yamashiro and all other colleagues contributing to the CHATT research project and to the preliminary design of the SpaceLiner.

\section{References}

${ }^{1}$ Sippel, M., Klevanski, J., Steelant, J.: "Comparative Study on Options for High-Speed Intercontinental Passenger Transports: Air-Breathing- vs. Rocket-Propelled", IAC-05-D2.4.09, October 2005

${ }^{2}$ Sippel, M., Schwanekamp, T., Trivailo, O..: "Progress of SpaceLiner Rocket-Powered High-Speed Concept", IAC-13D2.4.05, 64 ${ }^{\text {th }}$ International Astronautical Congress, Beijing, China, September 2013

${ }^{3}$ Gormely, T.F., Vaddey S. - Crossfeed Technologies for NLS Evolution, AIAA Space Programs and Technologies Conference, Huntsville, Alabama, USA, March 24-27, 1992

${ }^{4}$ Schwanekamp, T., Bütünley, J., Sippel, M.: "Preliminary Multidisciplinary Design Studies on an Upgraded 100 Passenger SpaceLiner Derivative", 18th AIAA/3AF International Space Planes and Hypersonic Systems and Technologies Conference, Tours, France, 2012

${ }^{5}$ Schwanekamp, T., Bauer, C., Kopp, A.: "The Development of the SpaceLiner Concept and its Latest Progress", $4^{\text {th }}$ CSA-IAA Conference on Advanced Space Technology, Shanghai, September 2011

${ }^{6}$ Sippel, M., Kopp, A., Mattson, D., Koussios, S.: "Advanced Cryo-Tanks Structural Design Investigated in CHATT", European Conference on Spacecraft Structures, Materials \& Environmental Testing, Braunschweig, Germany, April 2014

${ }^{7}$ Jenkins, D.R.: "Space Shuttle - The History of the National Space Transportation System - The First 100 Missions", Florida, 2010, ISBN-13: 978-0-9633974-5-4

${ }^{8}$ Sippel, M., Schwanekamp, T., Ortelt, M.: "Staged Combustion Cycle Rocket Engine Subsystem Definition for Future Advanced Passenger Transport”, Space Propulsion 2014, Cologne, Germany, May 2014

${ }^{9}$ Smith, G., Philips, A.: “Analysis of Parallel Burn, No-Crossfeed TSTO RLV Architectures and Comparison to Parallel Burn with Crossfeed and Series Burn Architectures", AIAA 2003-5244, 2003

${ }^{10}$ Stanley, D.O. et al.: “Conceptual Design of a Fully Reusable Manned Launch System”, Journal of Spacecraft and Rockets, Vol. 29, No. 4, July-August 1992

${ }^{11}$ Sosa, C.J. et al.: "Design and Integration of a Cryogenic Propellant Crossfeed System for Parallel Burn Vehicles", $29{ }^{\text {th }}$ AIAA/SAE/ASME/ASEE Joint Propulsion Conference and Exhibit, AIAA 93-2273, Monterey, CA, 1993

${ }^{12}$ Chandler, F. et al.: "Launch Vehicle Sizing Benefits Utilizing Main Propulsion System Crossfeed and Project Status", $38^{\text {th }}$ AIAA/SAE/ASME/ASEE Joint Propulsion Conference and Exhibit, AIAA 2002-3900, Indianapolis, Indiana, 2002

${ }^{13}$ Chandler, F. et al.: "The Importance of Detailed Component Simulations in the Feedsystem Development for a Two-Stageto-Orbit Reusable Launch Vehicle", $41^{\text {st }}$ AIAA/ASME/SAE/ASEE Joint Propulsion Conference and Exhibit, AIAA 2005-4370, Tucson, Arizona, 2005

${ }^{14}$ Nguyen, H., Mazurkivich, P.: "Development and Validation of a Pressurization System Model for a Crossfeed Subscale Water Test Article", 42 ${ }^{\text {nd }}$ AIAA/ASME/SAE/ASEE Joint Propulsion Conference and Exhibit, AIAA 2005-4371, Sacramento, California, 2006

${ }^{15}$ Nguyen, H. et al.: "Pressurization System Modeling for a Generic Bimese Two-Stage-to-Orbit Reusable Launch Vehicle", $41^{\text {st }}$ AIAA/ASME/SAE/ASEE Joint Propulsion Conference and Exhibit, AIAA 2005-4371, Tucson, Arizona, 2005

${ }^{16}$ Mehta, G. et al.: "Cavitation Prevention and Prediction", $31^{\text {st }}$ AIAA/ASME/SAE/ASEE Joint Propulsion Conference and Exhibit, AIAA 95-2959, San Diego, California, 1995

${ }^{17}$ Stinson, H.P. et al.: "Experimental Findings From Zero-Tank Net Positive Suction Head Operation Operation of the J-2 Hydrogen Pump", Marshall Flight Center, NASA, Washington DC, 1972

${ }^{18}$ Holster, J.: "Liquid Rocket Propellant Feedline Dynamics", $9^{\text {th }}$ AIAA/SAE Propulsion Conference, AIAA 73-1286, Las Vegas, Nevada, 1973 
${ }^{19}$ NN. FESTIP SS-16, TSTO-R-VTHL Concept FSS-9. Issue 1, Rev 3, 14-2-97, No: FSS-SCT-RP-0002

${ }^{20}$ EADS-ST, CNES-DLA - SRLV II - EVEREST Study Configuration Synthesis, TB6 No. 141024 , AVP-NT-2400000-0401-EALV-01, 2004

${ }^{21}$ Snecma Moteurs, CQ EPC A5E $\$ 3$ - INGENIERIE E.P.F., Presentation CQ EPC, FLTE 197/02, A5-DP-12-C-54-05ASET, 10.04.2002

${ }^{22}$ Schwanekamp, T.: "SpaceLiner 7-2 Propellant Crossfeed Studies in the Framework of the CHATT Project", DLR internal report, SART-TN-004/2013, Bremen, Germany, 2013 